\title{
Metagenomic analysis of an ecological wastewater treatment plant's microbial communities and their potential to
}

\section{metabolize pharmaceuticals [version 1; peer review: 1}

\section{approved, 1 approved with reservations]}

\author{
Ian N. Balcom ${ }^{1}$, Heather Driscoll2 ${ }^{2}$, James Vincent ${ }^{3}$, Meagan Leduc ${ }^{1}$ \\ ${ }^{1}$ Department of Natural Sciences, Lyndon State College, Lyndonville, VT, USA \\ ${ }^{2}$ Vermont Genetics Network, Department of Biology and Physical Education, Norwich University, Northfield, VT, USA \\ ${ }^{3}$ Vermont Genetics Network, Department of Biology, University of Vermont, Burlington, VT, USA
}

\section{V1 First published: $28 \mathrm{Jul}$ 2016, 5:1881 \\ https://doi.org/10.12688/f1000research.9157.1}

Latest published: $28 \mathrm{Jul} 2016, \mathbf{5 : 1 8 8 1}$

https://doi.org/10.12688/f1000research.9157.1
Open Peer Review

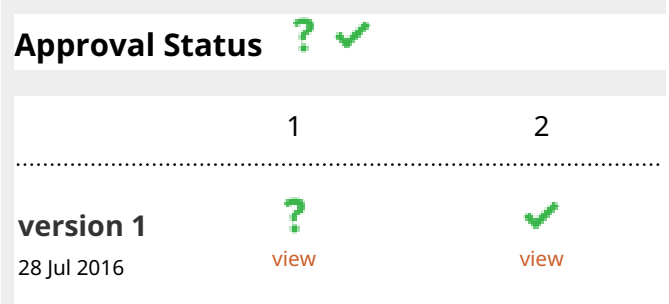

1. Benjamin C. Kirkup, US Naval Research

Laboratory, Washington, USA

2. Andrew C. Singer iD, NERC (Natural

Environment Research Council) Centre for

Ecology \& Hydrology (CEH) , Wallingford, UK

Any reports and responses or comments on the article can be found at the end of the article. 


\section{Keywords}

Wastewater treatment, microbial ecology, pharmaceuticals, micropollutants, metagenome, rhizoplane, eco-machine , biodegradation, biofilm

Corresponding author: Ian N. Balcom (ian.balcom@lyndonstate.edu)

Competing interests: The authors have no competing interests to declare.

Grant information: Research reported in this publication was supported by an Institutional Development Award (IDeA) from the National Institute of General Medical Sciences (NIGMS) of the National Institutes of Health (NIH) under grant number P20GM103449 awarded to INB through the Vermont Genetics Network (VGN). Its contents are solely the responsibility of the authors and do not necessarily represent the official views of NIGMS or NIH.

The funders had no role in study design, data collection and analysis, decision to publish, or preparation of the manuscript.

Copyright: ( 2016 Balcom IN et al. This is an open access article distributed under the terms of the Creative Commons Attribution License, which permits unrestricted use, distribution, and reproduction in any medium, provided the original work is properly cited. The author(s) is/are employees of the US Government and therefore domestic copyright protection in USA does not apply to this work. The work may be protected under the copyright laws of other jurisdictions when used in those jurisdictions.

How to cite this article: Balcom IN, Driscoll H, Vincent J and Leduc M. Metagenomic analysis of an ecological wastewater treatment plant's microbial communities and their potential to metabolize pharmaceuticals [version 1; peer review: 1 approved, 1 approved with reservations] F1000Research 2016, 5:1881 https://doi.org/10.12688/f1000research.9157.1

First published: 28 Jul 2016, 5:1881 https://doi.org/10.12688/f1000research.9157.1 


\section{Introduction}

The treatment of human wastewater by ecological systems predates the advent of engineered wastewater treatment plants (WWTPs). While exposure to human pathogens is greatly reduced in communities where modern wastewater treatment technologies have been implemented ${ }^{1}$, widespread detection of micropollutants in the environment ${ }^{2}$ raises serious concerns about the efficacy of modern WWTPs to treat this class of contaminants. Moreover, with about two-fifths of the world's population experience health effects due to poor sanitary conditions ${ }^{3}$. The emerging field of ecological engineering has provided a variety of viable, costeffective wastewater treatment designs ${ }^{4}$. The organizing principle of ecological wastewater treatment is the construction of "task oriented mesocosms" $", 6$ of eutrophic ecosystems that, like conventional systems, primarily rely on microbial metabolic processes to achieve water quality goals. Where ecological WWTPs and conventionally engineered WWTPs differ significantly is in their reliance on ecological processes to assimilate nitrogen, phosphorous, and carbon from the wastewater into biomass. Whereas, conventional WWTPs utilize mechanically assisted, microbial processes to evolve gaseous $\mathrm{C}, \mathrm{N}$, and frequently chemical precipitation of phosphorous. A number of ecological systems have been operating around the world for decades including constructed wetlands $s^{7,8}$, Eco-Machines $^{\mathrm{TM} 4}$, and biofilters ${ }^{9,10}$ for residential, industrial, and municipal wastewater. These systems perform reliably based on tertiary wastewater standards ${ }^{4}$, while reducing operational costs ${ }^{11}$ and environmental and human health impacts of wastewater ${ }^{12}$. The unique potential provided by ecologically engineered waste management is direct conversion of a liability (i.e. wastewater) to an asset (sequestered carbon, biomass, products, biodiversity, etc. $)^{13}$.

At the core of wastewater treatment is the biodegradation, oxidation, and reduction of organic macromolecules and inorganic chemical species primarily by resident microbial communities. While the microbial communities of conventional WWTPs have been thoroughly studied ${ }^{14}$, very little is known about microbial communities in existing ecological WWTPs despite the fact that they are central to the functions these systems provide ${ }^{6}$. The introduction of activated sludge and environmental media from diverse sources is thought to provide essential microbial functional groups $s^{4,15}$. It is not known whether these "seeding" events provide microbial functional groups with the capacity for biodegradation of micropollutants.

The promotion of microbial biodegradation of recalcitrant xenobiotic pollutants by plant roots has been well documented ${ }^{16,17}$. The "rhizosphere effect" ${ }^{18-20}$, driven by the release of plant metabolites from plant roots, accelerates microbial biodegradation of recalcitrant pollutants in soil and water ${ }^{21,22}$. In some cases, microbial biodegradation is promoted by a nonspecific increase in microbial metabolic activity in the area surrounding roots ${ }^{23}$, yet other studies have shown a relationship between specific plant metabolites and certain pollutant degrading organisms ${ }^{24}$. The interaction has been described as co-metabolic induction, or "co-metabolism", where metabolism for one compound is promoted in the presence of other compounds ${ }^{21,22}$. This phenomenon has been successfully employed to accelerate the removal of a variety of recalcitrant pollutants from the soil and water including polychlorinated biphenols (PCBs) $)^{19,20,24}$, polycyclic aromatic hydrocarbons ${ }^{22}$, and chlorinated solvents such as trichloroethylene ${ }^{25}$. However, little research has been done on whether co-metabolism is occurring in ecological WWTPs as a result of plant-microbe feedback processes. Using whole metagenome sequencing (WMS) we have examined whether the microbial populations residing on the plant roots immersed in wastewater of an ecological WWTP showed evidence of the capacity for micropollutantant biodegradation. These populations were compared to microbial communities free-floating in the wastewater, enrichment cultures growing on individual pharmaceutical compound carbon sources, as well as PPCP concentrations throughout the treatment system to determine whether plant-microbe feedback processes are supporting PPCP biodegradation in ecological WWTPs.

\section{Materials and methods}

Materials

Carbamazepine (5H-Dibenz $[b, f]$ azepine-5-carboxamide), sulfamethoxazole (4-Amino- $N$-(5-methyl-3-isoxazolyl)benzenesulfonamide), and trimethoprim (2,4-Diamino-5-(3,4,5-trimethoxybenzyl)pyrimidine) were purchased from Sigma Aldrich.

\section{EcoMachine $^{\mathrm{TM}}$ sampling}

An ecological WWTP (Eco-Machine ${ }^{\mathrm{TM}}$ ) in Sharon, Vermont at the Vietnam Memorial rest area on northbound Interstate 89 (43.727896, -72.425564) was sampled on June 30 and July 1, 2013. Wastewater from the toilets, urinals, and sinks, is collected in a holding tank and then treated in a series of tanks (Figure 1). These consist of an anoxic tank (ANOX), a closed tank (CLO) and planted aerobic tanks (HR1, HR2 and HR3). These are followed by a clarifier and final treatment by a sand filter (SAND). The treated water (effluent, hereafter) is disinfected with the addition of sodium hypochlorite and dyed blue prior to returning to the toilets and urinals for reuse. To accommodate the approximately 48 hour residence time of the wastewater in the system [personal communication-Phil Gates, Simon Management Services], samples of aqueous phase and the immersed biofilm were collected from the first three tanks (ANOX, CLO, HR1) on June 30, 2013 and the latter three tanks (HR2, HR3, and SAND) on July 1, 2013. Plant root biofilm samples consisted of multiple roots from each individual tank composited into one sample. Influent wastewater samples (INF) were collected from the holding tank on June $30^{\text {th }}$.

\section{PPCP quantification}

Duplicate $1 \mathrm{~L}$ aqueous phase samples were collected from each of the treatment tanks as well as the system INF and effluent (EF) for quantification of PPCPs by EPA method $1694^{26,27}$ at a commercial analytical lab (TestAmerica, Sacramento, CA) using the Waters Acquity UPLC System and Waters Micromass Quattro Premier XE Mass Spectrometer.

\section{Enrichment cultures}

Enrichment cultures with the pharmaceutical compounds carbamazepine, trimethoprim, and sulfamethoxazole $(0.1 \mathrm{M})$ serving as individual carbon sources were initiated using wastewater effluent inoculum in $100 \mathrm{~mL}$ carbon-free mineral salts medium $(10 \mathrm{mM}$ $\mathrm{KH}_{2} \mathrm{PO}_{4}, 3 \mathrm{mM} \mathrm{NaH} \mathrm{PO}_{4}, 1 \mathrm{mM} \mathrm{MgSO}, 1 \mathrm{mM} \mathrm{NH}_{4} \mathrm{SO}_{4}$ and trace minerals ${ }^{28}$ ). Carbamazepine was delivered with minimal amounts of methanol added to the flask immediately after autoclaving and was allowed to evaporate leaving small suspended crystals as the 

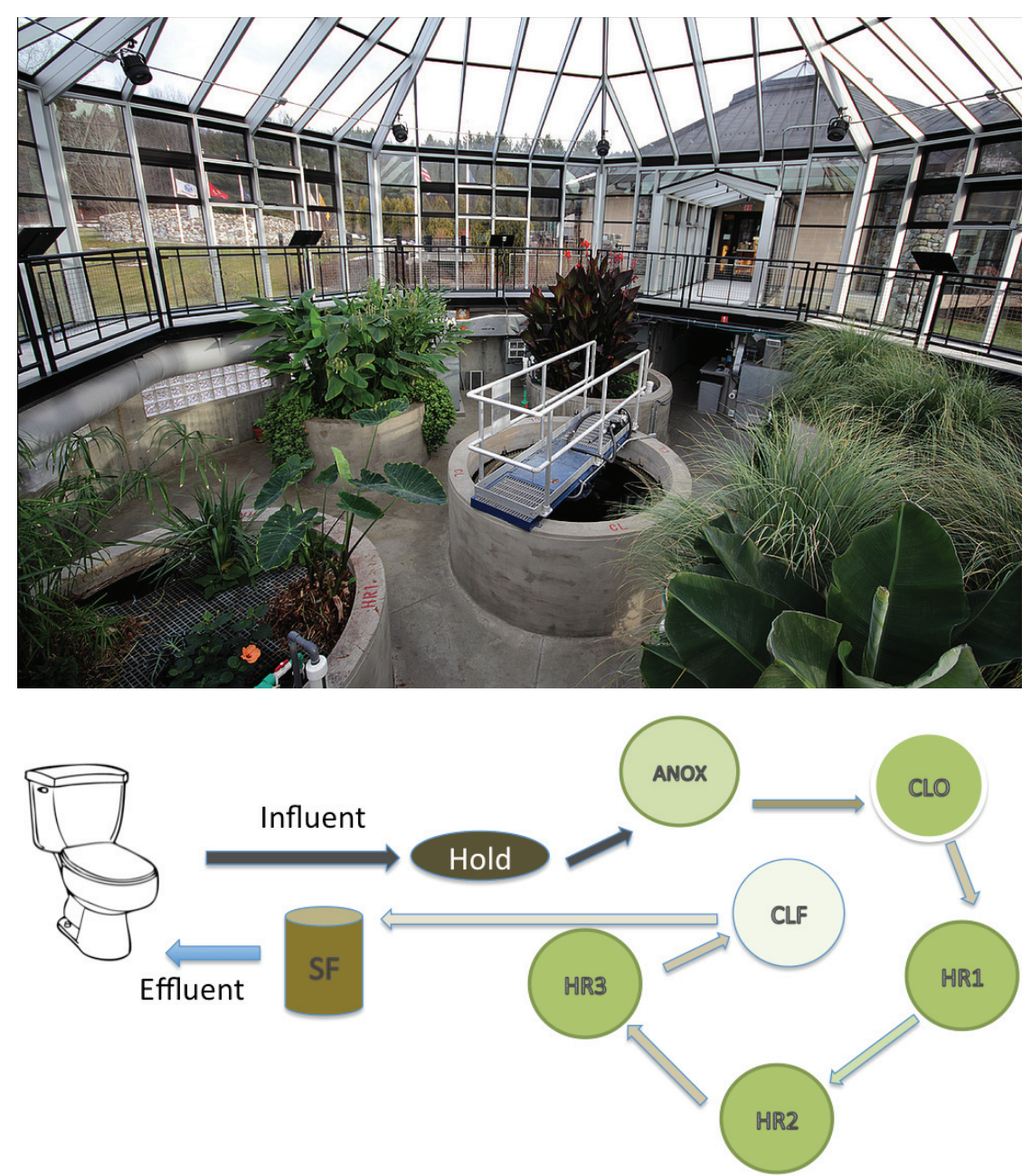

Figure 1. System layout of the Vermont, Vietnam Memorial and Visitor Center ecological WWTP. Abbreviations: Hold - holding tank, ANOX- anoxic tank, CLO- closed tank, HR1, HR2 and HR3- planted aerobic tanks, CLF- clarifier, SF sand filter.

sole carbon source. Starting with $1 \mathrm{~mL}$ of the WWTP sample, enrichment cultures were maintained at room temperature in a rotary shaker (100 rpm) for approximately 90 days. Five replicate cultures were initiated for each individual pharmaceutical carbon source.

At the third serial enrichment samples from the carbamazepine cultures $(\mathrm{C} 3 \mathrm{~A}, \mathrm{C} 3 \mathrm{~B}$, and $\mathrm{C} 3 \mathrm{D})$, trimethoprim cultures (T3B, T3C , and $\mathrm{T} 3 \mathrm{D})$ and sulfamethoxazole cultures (S3B, and S3D) were selected based on visual verification of microbial growth in the flasks. These eight samples were used for all further analyses.

\section{Genomic DNA extraction}

Total genomic DNA was extracted and combined from duplicates for all samples using the following methods: water, biofilm, and enrichment culture samples were centrifuged at $>8,000 \mathrm{~g}$ for $1 \mathrm{~min}$. Excess liquid was removed and pellets containing microbial samples were homogenized. Homogenization was performed using $300 \mathrm{mg}$ of a 50/50 mix of $1 \mathrm{~mm}$ and $100 \mu \mathrm{m} \mathrm{AlO}_{3}$ abrasive and 1 1/4 $\mathrm{mm}$ ceramic ball (Matrix F equivalent-MP Biomedical) and FastPrep-24 (MP Biomedicals, Santa Ana, CA) for $20 \mathrm{sec}$. at $6.5 \mathrm{R} / \mathrm{S} .10 \mu \mathrm{L}$ of $10 \mu \mathrm{g} / \mu \mathrm{L}$ lysozyme (Sigma), $4 \mu \mathrm{L}$ of $400 \mathrm{U} / \mu \mathrm{L}$ Achromopeptidase (Sigma), $2 \mu \mathrm{L}$ Mutanolysis $(5 \mathrm{U} / \mu \mathrm{L})$ prepared in $10 \mathrm{mM}$ TRIS buffer were added to each sample, which were briefly vortexed and incubated overnight at $37^{\circ} \mathrm{C}$. The samples were then extracted using the standard method outlined by the E.Z.N.A. ${ }^{\circledR}$ Mollusc DNA isolation kit (Omega-Biotek, Inc, Norcross, GA), and the resulting DNA was quantified and its quality was assessed using the Nanodrop spectrophotometer (Thermo Scientific, Madison, WI), and Qubit Spectrofluorometer (Life Technologies, Carlsbad, CA) according to manufacturer's instructions. After duplicate samples were combined, the resulting DNA concentrations were between $1.1 \mathrm{ng} / \mu \mathrm{L}$ for the wastewater samples obtained from tanks HR1 and HR2 and $17.9 \mathrm{ng} / \mu \mathrm{L}$ for the biofilm sample collected from the anoxic tank. Fragmentation of 10-100 ng of the resulting DNA was performed using a Covaris S2 AFA sonicator (Covaris Corp., Woburn, MA) equipped with MicroVails (http://covarisinc.com/ products/afa-tubes-and-vials/microtube-15/) to yield a size range of 200-500 bp as confirmed through a high sensitivity microfluidic DNA chip on the Bioanalyzer 2100 (Agilent Technologies, Santa 
Clara, CA) according to the manufacturer's instructions. The Agilent 2100 Bioanalyzer is an automated microfluidic-chip that is widely used to assess the DNA size fragment distribution and quantification in next-generation sequencing.

\section{Illumina ${ }^{\circledR}$ library preparation}

Library preparation was performed using $45 \mathrm{ng}$ of DNA (except samples HR1_W and HR2_W, which produced a total of $33 \mathrm{ng}$ of DNA) in accordance with the Illumina ${ }^{\circledR}$ TruSeq DNA Sample Prep LT version 2 SOP (Part \# 15026486 Rev. C, July, 2012) with the indicated reagents (DNA kit \#FC-121-2001). According to manufacturer's instructions, each sample was subjected to end repair, adenylation, and ligation of Illumina adaptors for indexing purposes. PCR amplification was performed using Illumina reagents (Part\#15012995) followed by quantification using the Qubit spectrofluoromter and qPCR quantitation kit (KAPA Biosciences kit \# 4824). Library quality and insert size distribution was assessed using the Agilent Bioanalyzer 2100.

\section{Massively parallel sequencing}

Cluster generation and paired-end sequencing were performed at the Delaware Biotechnology Institute (DBI), University of Delaware, using an eight lane high-capacity v3 flowcell on the Illumina cBOT and HiSeq 2000 sequencer (Illumina, San Diego, CA), respectively. The WWTP samples (twelve) and the enrichment culture samples (eight) were multiplexed and run on two lanes. DBI delivered 20 FASTQ files with raw sequence data.

\section{Sequence processing}

Raw sequences were checked for quality with FastQC v0.10.1 (http://www.bioinformatics.babraham.ac.uk/projects/fastqc/). Trimmomatic $\mathrm{v} 0.30^{29}$ was used to remove adapters and filter lowquality base calls/reads. Leading and trailing bases below quality 20 and reads less than 40 bases in length were removed. Additionally, reads were scanned using a 5-base wide sliding window and cut when the average quality per base dropped below 20. PhiX Control v3 from Illumina was used as a low-concentration spikein during sequencing at DBI. Quality-trimmed FASTQ files were aligned to the PhiX genome (NCBI RefSeq NC_001422.1) using Bowtie2 2.2.3 $3^{30}$ and all aligned reads were removed. Qualitytrimmed and filtered reads were verified with FastQC prior to taxonomic and functional characterization.

\section{Nucleotide sequence accession numbers}

All twenty FASTQ files and associated metadata are available through NCBI BioProject ID PRJNA286671 (http://www.ncbi. nlm.nih.gov/bioproject/286671).

\section{Bioinformatic analysis}

Translated trimmed reads served as input for a protein-level homology search against NCBI-NR, (ftp://ftp.ncbi.nlm.nih.gov/ blast/db/FASTA/nr.gz, downloaded May 26, 2015) a comprehensive non-redundant protein database, using the BLAST-like tools RAPSearch2 v2.16 $6^{31}$ for WWTP samples and DIAMOND v.0.7.9 $9^{32}$ for enrichment culture samples. DIAMOND was used instead of RAPSearch2 for analysis of enrichment culture samples because it was designed to easily integrate with MEtaGenome
ANalyzer (MEGAN). It implements an algorithm that is similar to, but faster than, RAPSearch2, it was newly available when the enrichment cultures' sequence data was ready for analysis, and control sample testing showed nearly identical taxonomic profiles from DIAMOND as those generated with RAPSearch2 searches.

The similarity search results for each sample set, which include all reads with alignments to the NR protein database and their GI accession numbers (maximum 25 alignments per read) were imported separately into MEGAN v5.7.10 ${ }^{33}$ (http://ab.inf.uni-tuebingen.de/software/megan5/). MEGAN parsed the RAPSearch2 (WWTP) and DIAMOND (enrichment culture) results using the lowest common ancestor (LCA) algorithm ${ }^{34}$ and NCBI taxonomy (ftp://ftp.ncbi.nlm.nih.gov/pub/taxonomy/taxdmp.zip downloaded March 26, 2015) (lowest common ancestor parameters: maxMatches $=100$ minScore $=50.0$ maxExpected $=1.0$ topPercent $=$ 10.0 minSupportPercent $=1.0$ minSupport=50 minComplexity= 0.44). Reads that passed this filter and that were unambiguously assigned to a NCBI taxon by LCA were retained in each sample's MEGAN results file. A combined MEGAN file was generated for WWTP samples, as well as for enrichment culture samples, with read counts normalized to the sample with the fewest input reads in each set.

Two positive controls were used to validate our bioinformatics pipeline and to establish a minimum support threshold (or falsepositive cut-off) for taxonomic profiling. One control dataset is comprised of single-end Illumina reads from a synthetic microbial sample prepared by CosmosID. This constructed freshwater sample simulates organisms found in the Delaware River and is described here: http://www.cosmosid.net/constructed-freshwater. The second control dataset is single-end Illumina reads from the Human Microbiome Project (HMP) mock community even sample (http://www.ncbi.nlm.nih.gov/sra/SRX055380). Reads from both positive control samples can be downloaded from BaseSpace: https://basespace.illumina.com/projects/20039022/samples.

Using MEGAN, reads were annotated based on the KEGG (Kyoto Encyclopedia of Genes and Genomes) functional classification of enzymes and pathways ${ }^{36}$. Using auxiliary index files obtained from the MEGAN website (gi2kegg.map.gz, built Dec 1, 2010), GI accession numbers were mapped to KEGG functional groups based on the highest MinScore match (minimum MinScore = 50). Reads may be assigned to more than one functional group per classification system, as each KEGG group may appear in several functional categories.

The relatedness of the microbial communities located in the different tanks and phases of the WWTP was assessed through pairwise similarity scores computed in MEGAN using a normalized Goodall's probabilistic similarity index ${ }^{38}$ for both phylogenetic and metabolic profiles for each sample. Graphical representations of the distance matrices were generated in MEGAN as un-rooted phylogenetic neighbor networks ${ }^{39}$. A Venn diagram was produced (Partek $^{\circledR}$ Genomics Suite ${ }^{\circledR}$ software, version 6.6 build 6.15.1016 Copyright; 2014, Partek Inc., St. Louis, MO, USA) to illustrate taxa common to the different sample datasets. 
Statistical Analysis of Metagenomic Profiles (STAMP) software v2.1.3 $3^{40}$ was used to test statistical significance of differentially abundant taxonomic groups and functional categories for 1) WWTP sample groups (aqueous and biofilm phases) and 2) enrichment culture sample groups (carbamazepine (C), sulfamethoxazole (S), and trimethoprim (T)). LCA taxonomic profiles and KEGG including abundances, were imported to STAMP for each sample set. Two-sided Welch's t-test was used to compare aqueous and biofilm phases with a confidence interval of the effect size and multiple test correction using the Benjamini-Hochberg FDR method. One-way ANOVA was used to compare enrichment culture groups with an effect size (Eta-squared) and multiple test correction using the Benjamini-Hochberg FDR method. Tukey-Kramer post-hoc test (0.95) was used to determine which means were significantly different when an ANOVA produced a significant $\mathrm{p}$-value.

To visualize the distribution of microbial taxa in WWTP samples the Circos software package v0.69 $9^{41}$ was used to depict the location and relative abundances of microbial taxa at the class rank identified in MEGAN using the LCA algorithm.

\section{Results}

\section{PPCPs concentrations}

There were 11,568 visitors during the week in which sampling was conducted (June 25-July 1, 2013). Each visitor used an average of 2.27 liters of water contributing 26,452 liters of water to the wastewater treatment system ${ }^{42}$. The wastewater used to isolate microbial DNA samples contained detectable concentrations of caffeine, carbamazepine, DEET, gemfibrozil, ibuprofen, naproxen, sulfamethoxazole, thiabendazole, and trimethoprim. Of the compounds detected in influent water (from facility toilets, urinals, and sink drains), the cholesterol medication gemfibrozil was detected at the highest concentration $\left(1.5 \times 10^{5} \mathrm{ng} \mathrm{L}^{-1}\right)$, followed by caffeine, ibuprofen, and naproxen $\left(9.5,6.6\right.$, and $5.5 \times 10^{4} \mathrm{ng} \mathrm{L}^{-1}$, respectively) (Table 1). The concentrations of PPCPs in the wastewater samples generally decreased the further through the treatment process (Figure 1) the sample was obtained. However, gemfibrozil, caffeine, and ibuprofen were detected at higher concentrations in the sand filter or effluent water samples than the preceding tank.
The concentrations of carbamazepine, DEET, and trimethoprim did not change substantially over the entire treatment process.

\section{Metagenome sequencing and sequence processing}

Whole metagenome shotgun sequencing of 12 WWTP samples generated more than 388 million paired-end reads, $101 \mathrm{bp}$ in length, with an average depth of 32.4 million reads per sample (range: 2.35-53.3 million) (Supplementary Material ST13). Eighty-eight percent of raw reads $(343,355,560)$ were retained after qualitytrimming and were aligned to the NCBI-NR protein database. Of the $175,238,945$ reads with at least one hit to NR proteins, approximately $84 \%$ were assigned taxonomy by the lowest common ancestor (LCA) algorithm in MEGAN. Over half of quality-trimmed reads in our samples $(51 \%)$ had no protein hits in NCBI-NR and $19.3 \%$ of reads with protein hits could not be classified by the LCA algorithm. As a result, the latter were designated "Not Assigned" reads in MEGAN.

Whole metagenome shotgun sequencing of the 8 enrichment culture samples generated more than 177 million paired-end reads, $101 \mathrm{bp}$ in length, with an average depth of 22 million reads per sample (range: 17-29 million) (Supplementary Material ST14). Eighty-nine percent of raw reads $(157,598,266)$ were retained after quality-trimming and were aligned to the NCBI-NR protein database. Of the $96,824,600$ reads with at least one hit to NR proteins, over $99 \%$ were assigned taxonomy by the LCA algorithm in MEGAN. Nearly $39 \%$ of quality-trimmed reads in our samples $(60,773,666)$ had no protein hits in NCBI-NR and $0.4 \%$ of reads with protein hits could not be classified by the LCA algorithm and were designated "Not Assigned" reads in MEGAN. The minimum-support percent threshold in MEGAN for both WWTP and enrichment culture analyses was set to $1.0 \%$ based on our bioinformatics workflow results from the HMP and Delaware River control samples.

\section{Taxonomic classification of sequences}

The LCA algorithm provided a microbial taxonomic profile of the 12 WWTP samples and the 8 enrichment culture samples (Figure 2 and Figure 3, respectively). The read counts were normalized to

Table 1. Concentrations of detected pharmaceutical compounds in the ecological

wastewater treatment plant. Concentrations $\left(\mathrm{ng} \mathrm{L}^{-1}\right)$ of detected pharmaceuticals and personal care products in the wastewater sampled from each major treatment tank of the WWTP. Abbreviations: INF- influent, ANOX-anoxic closed tank, CLO-closed aerobic tank, HR1, HR2 \& HR3- planted aerobic tanks, SF- sand filter, EF- fffluent, Caff- caffeine, Carb- carbamazepine, DEET - N,N-Diethyl-3-methylbenzamide, Gemf- gemfibrozil, Ibup- ibuprofen, Napr- naproxen, Sulf- sulfamethoxazole, Thiathiabendazole, Trim- trimethoprim, ND-not detected above method reporting limit.

\begin{tabular}{|l|r|r|r|r|r|r|r|r|r|}
\hline & Caff & Carb & DEET & Gemf & lbup & Napr & Sulf & Thia & Trim \\
\hline INF & 95000 & ND & ND & 150000 & 66000 & 55000 & 7700 & 12000 & ND \\
\hline ANOX & 19000 & 770 & 640 & 3500 & 11000 & 6500 & 2900 & ND & 550 \\
\hline CLO & 4800 & 730 & 620 & 3600 & 2100 & 3000 & 2000 & ND & 290 \\
\hline HR1 & 1300 & 590 & 540 & 1100 & 560 & 1600 & 1100 & ND & 450 \\
\hline HR2 & 602 & 540 & 520 & 890 & 300 & 540 & 980 & ND & 420 \\
\hline HR3 & 510 & 530 & 550 & 770 & ND & ND & 930 & ND & 480 \\
\hline SF & 1000 & 590 & 540 & ND & ND & ND & 960 & ND & 490 \\
\hline EF & 570 & 550 & 560 & 2400 & 340 & ND & 860 & ND & 460 \\
\hline
\end{tabular}




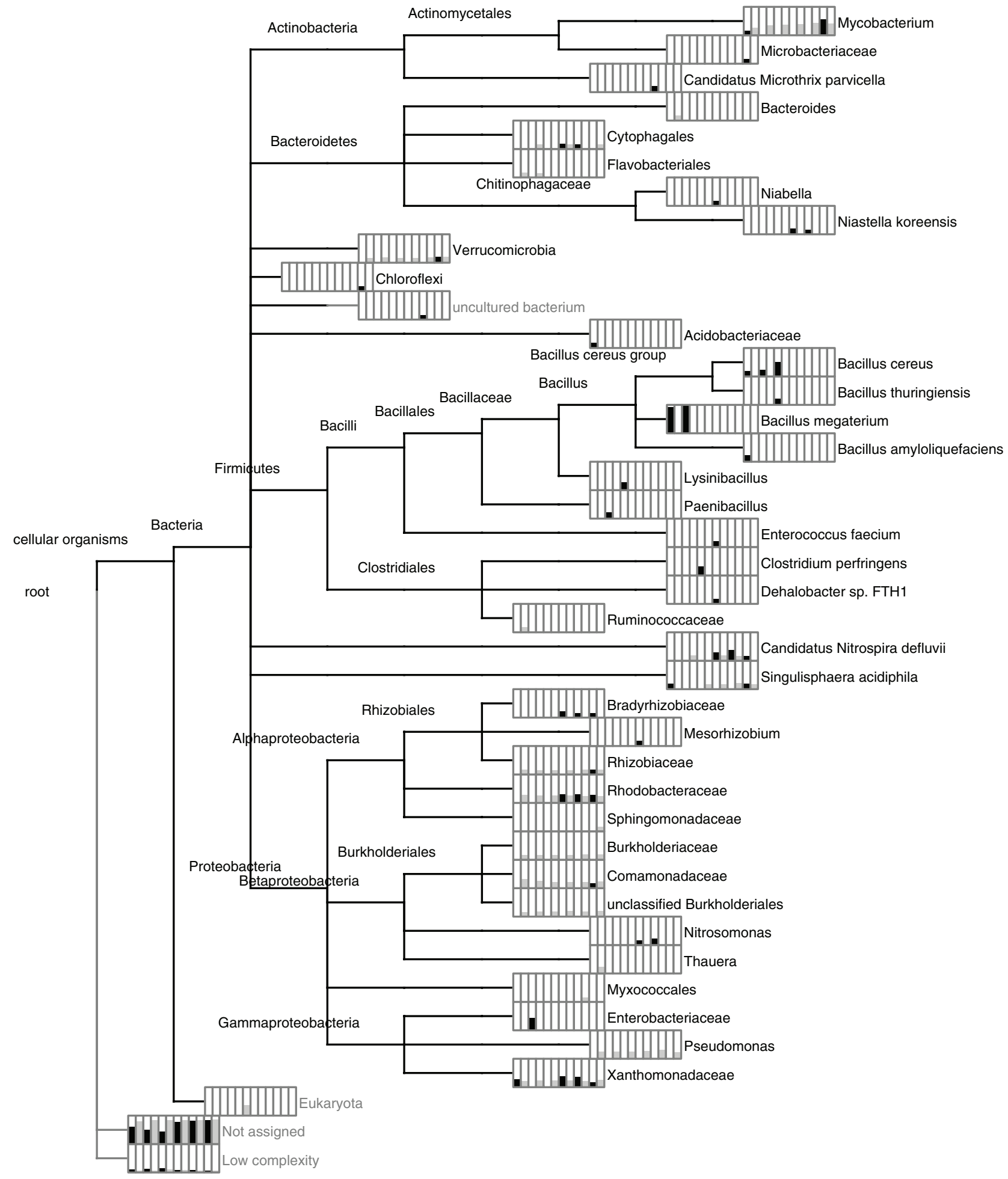

Legend:

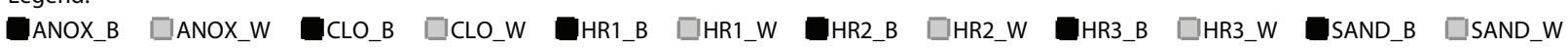

Figure 2. Taxonomic composition and relative abundance of the ecological wastewater treatment plant's microbial communities. Phylogram depicting the lowest common ancestor taxonomic composition of the ecological wastewater treatment plant. Bar chart for each taxon (depicted in the order shown in the legend) indicate the number of reads (normalized) associated with each taxonomic classification, shown here in square-root scale to highlight differences. Wastewater treatment plant sample locations with _W and _B indicate aqueous and immersed biofilm samples, respectively. Abbreviations: ANOX-anoxic tank, CLO- closed aerobic tank, HR1, HR2 and HR3- planted aerobic tanks, and SAND - sand filter. 


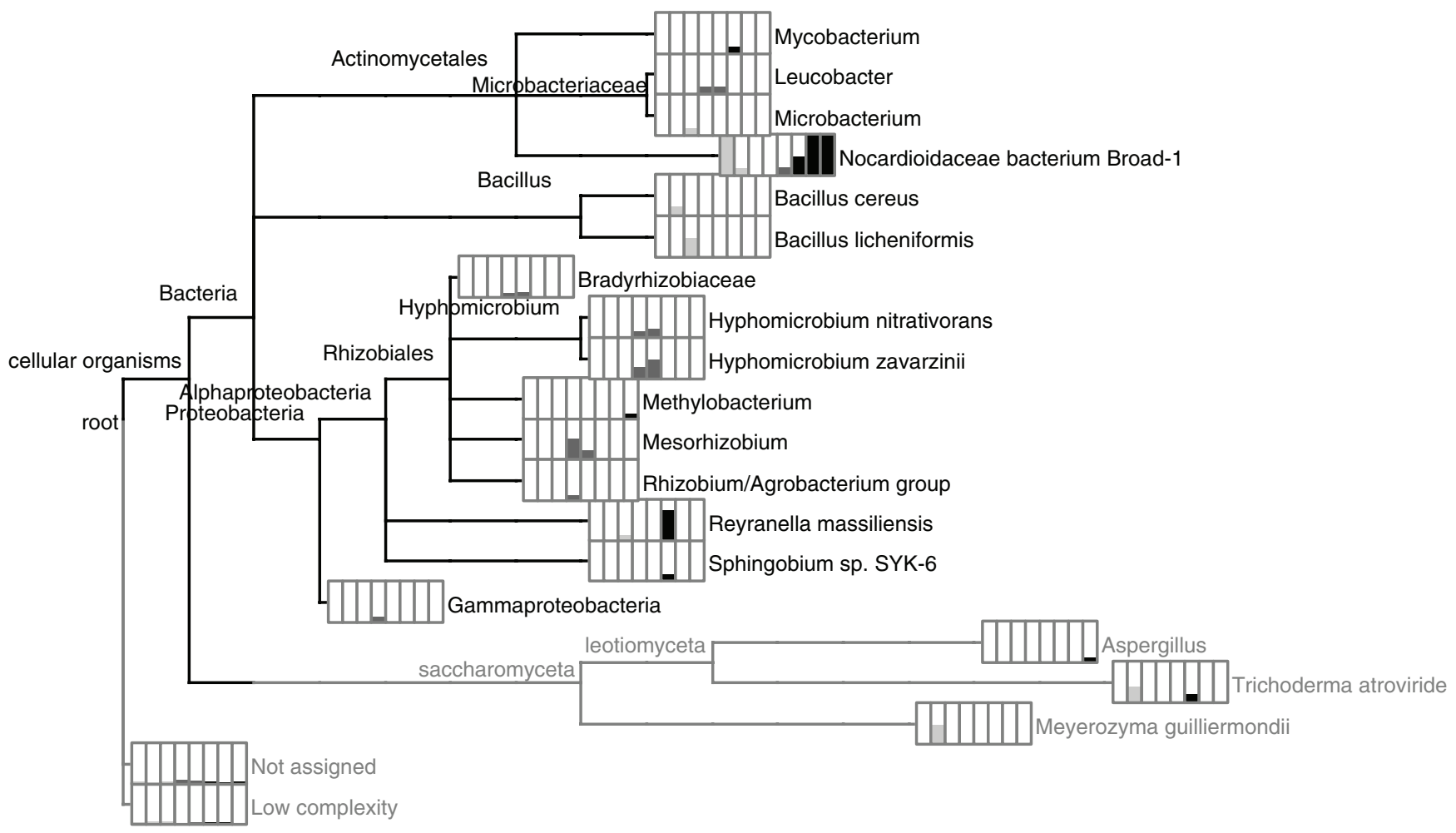

Legend:

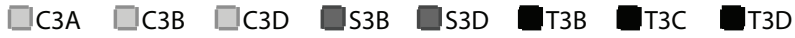

Figure 3. Taxonomic composition and relative abundance of the pharmaceutical-degrading liquid enrichment cultures. Phylogram depicting the lowest common ancestor taxonomic composition of the sole pharmaceutical compound carbon source enrichment cultures. Bar charts for each taxon (depicted in the order shown in the legend) and indicate the number of reads (normalized) associated with each taxonomic classification, shown here in square-root scale to highlight differences. Samples starting with $\mathrm{C}$, T, and $\mathrm{S}$ indicate sequences obtained from cultures grown on carbamazepine, trimethoprim, and sulfamethoxazole carbon sources, respectively.

the sample with the least number of total reads to allow relative abundance to be depicted and shown as bar-charts at the leaves of each phylogram. The terminal taxa from various ranks identified by the LCA algorithm in the 12 WWTP samples ranged from a low of 8 taxa (HR1_B sample) to 17 taxa (ANOX_W sample) (Figure 2; Supplementary Material ST2). Members of Mycobacterium, Pseudomonas, and Verrucomicrobia were identified in all of the aqueous phase (_W) samples as well as the biofilm in the anoxic tank (ANOX_B) and the sand filter (SAND_B). Additionally, the families Rhodobacteraceae, Burkholderiaceae, Comamonadaceae and Xanthomonadaceae were identified in all of the aqueous phase samples as well as in at least one, but not all immersed biofilm samples. The family Xanthomonadaceae was identified in 10 of the 12 WWTP samples, followed by Rhodobacteraceae (9), Comamonadaceae and Rhizobiaceae (7), and Burkholderiaceae (6).

According to the LCA algorithm taxonomic assignments by MEGAN, the enrichment cultures originating from the wastewater effluent inoculant produced mixed cultures ranging from 2 (T3B and T3C) to 8 (S3D) taxa identified in each culture (Figure 3; Supplementary Material ST4). Bacteria were identified in all enrichment cultures and ascomycete fungi were in all carbamazepine cultures and one trimethoprim culture (T3D). The family Nocardioidaceae in the Propionibacterineae was identified in all but two of the cultures (C3D and S3B). Proteobacteria were identified in all but one of the carbamazepine cultures $(\mathrm{C} 3 \mathrm{~B})$. Alphaproteobacteria was identified in two carbamazepine cultures (C3A and C3D), all sulfamethoxazole cultures as well as one of the trimethoprim cultures (T3D). Gammaproteobacteria was identified in one sulfamethoxazole culture (S3B). Numerous taxa were identified at the species level by LCA in MEGAN, including Bacillus cereus, B. lichenfomis, B. subtilis, Clostridium perfringens, Hyphomicrobium denitrificans, $H$. nitrativorans, $H$. zavarzinii, Sphingobium sp. SYK-6, Trichoderma atroviride, T. virens, and Meyerozyma guilliermondii.

The carbamazepine cultures (C3A, C3B, and C3D) all contained members of Actinomycetales, Ascomycete fungi, while Firmicutes and Alphaproteobacteria are represented in two of three replicates (C3B, C3D and C3A, C3D, respectively). Similarly, the trimethoprim enrichment cultures (T3B, T3C and T3D) contained Actinomycetes and Proteobacteria with Alphaproteobacteria and ascomycete budding yeast fungus Aspergillus in culture T3D only. The sulfamethoxazole enrichment cultures contained highest taxonomic richness with eight taxa identified by LCA in MEGAN in one of the replicates (S3D) and seven taxa in the other (S3B). These taxa collectively included members of the Actinomycetales (Leucobacter), Rhizobiales (Bradyrhizobiaceae, Hyphomicrobium, Mesorhizobium, Rhizobium/Agrobacterium group), and Gammaproteobacteria. 
A graphical representation of the pairwise distance matrix ${ }^{39}$ generated using normalized Goodall's similarity index ${ }^{38}$ of the 12 WWTP samples is shown as an unrooted phylogenetic neighbor network in Figure 4. The LCA taxonomic assignments of the microbial populations residing in the aqueous phase samples cluster near one another in the neighbor network, while the immersed biofilm samples showed greater dissimilarity.

In STAMP, the aqueous and biofilm samples were compared at different taxonomic ranks to highlight differences between the WWTP sample sets. Figure 5 depicts the percent relative abundances of microbial classes identified in the 12 WWTP samples. In general, Actinobacteria, Alphaproteobacteria, Betaproteobacteria, and Gammaproteobacteria had higher relative abundances in the aqueous samples, whereas Bacilli were more abundant in the biofilm samples. The relative abundances of Bacilli in the biofilm samples were highest in the first three tanks (ANOX, CLO, HR1) and sharply reduced thereafter (Figure 5a, Figure 9). The relative abundances of Deltaproteobacteria, Betaproteobacteria, Gammaproteobacteria, and Bacilli were significantly different between the two physical phases (aqueous and biofilm) sample sets (Figure 5b).

To assess similarities in taxonomic composition between the pharmaceutical compound enrichment cultures and the WWTP samples, we examined the co-occurrence of LCA taxa among datasets (Figure 6). The taxonomic similarities of the five major sample types were examined by combining all aqueous samples, all immersed biofilm samples, and the replicates of each pharmaceutical carbon source enrichment cultures into five datasets. As is typical of enrichment cultures originating from complex environmental samples, taxonomic similarities were limited to a few shared taxa. When combined, twelve microbial taxa were identified in the carbamazepine enrichment cultures. However, only three taxa were identified in at least two out of three replicate carbamazepine cultures. Of the twelve taxa identified in the combined carbamazepine cultures, only one each was identified in the biofilm and aqueous samples (Bacillus cereus, Mycobacterium spp., respectively) obtained from the wastewater treatment plant. Bacillus cereus was identified in the biofilm samples obtained from the first three tanks of the wastewater treatment system (ANOX_B, CLO_B, and HR1_B). It has been associated with human feces ${ }^{43}$. One taxon (Nocardioidaceae bacterium Broad-1) was found in six out of eight total enrichment culture samples, including all three trimethoprim samples. Additionally, Proteobacteria, Aspergillus spp. and Methylobacterium spp. were unique to trimethoprim enrichment cultures. Nocardioidaceae bacterium Broad-1, found as a byproduct during the genome assembly of the fungus Coccidioides (NCBI BioProject accession number PRJNA48513), is of unknown origin. Of the ten taxa identified in the combined sulfamethoxazole cultures, $50 \%$ were in both sulfamethoxazole samples, three were identified in the biofilm samples (Rhizobiaceae (HR2_B, HR3_B and Sand_B), Bradyrhizobiaceae (Sand_B), and Mesorhizobium spp. (HR2_B)), and one was found in the all of the aqueous samples (Rhizobiaceae) obtained from the wastewater treatment plant. Seven out of 40 WWTP taxa were shared among the aqueous and biofilm samples.

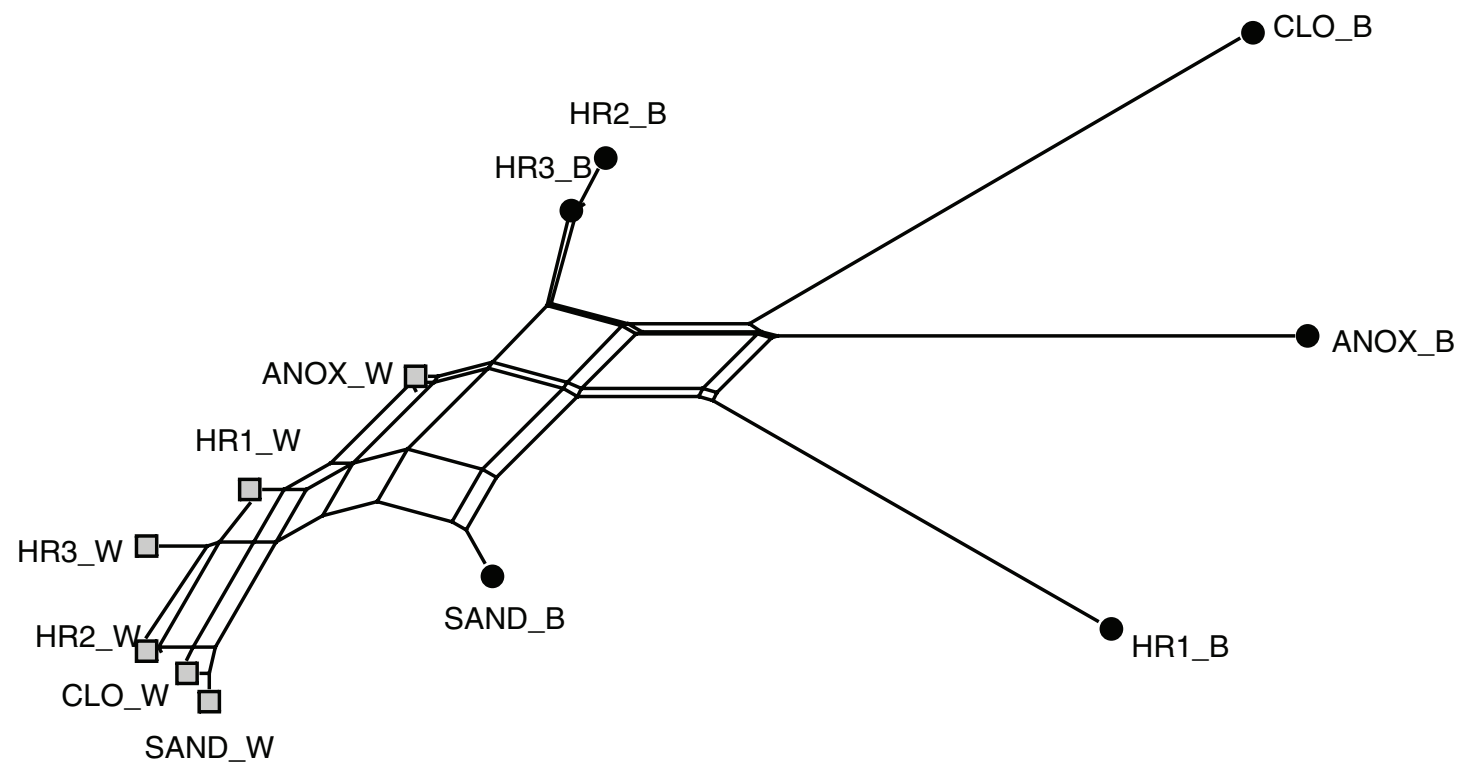

Figure 4. Taxonomic structure of the ecological wastewater treatment plant's microbial communities. Neighbor-net depicting the taxonomic pairwise similarity (Normalized Goodall) of the lowest common ancestor of translated sequences obtained from the six major tanks of the WWTP and the two major phases (aqueous_W and immersed biofilm_B) of the ecological wastewater treatment plant. Abbreviations: ANOX - anoxic tank, CLO - closed aerobic tank, HR1, HR2 and HR3 - planted aerobic tanks, and SAND - sand filter. 


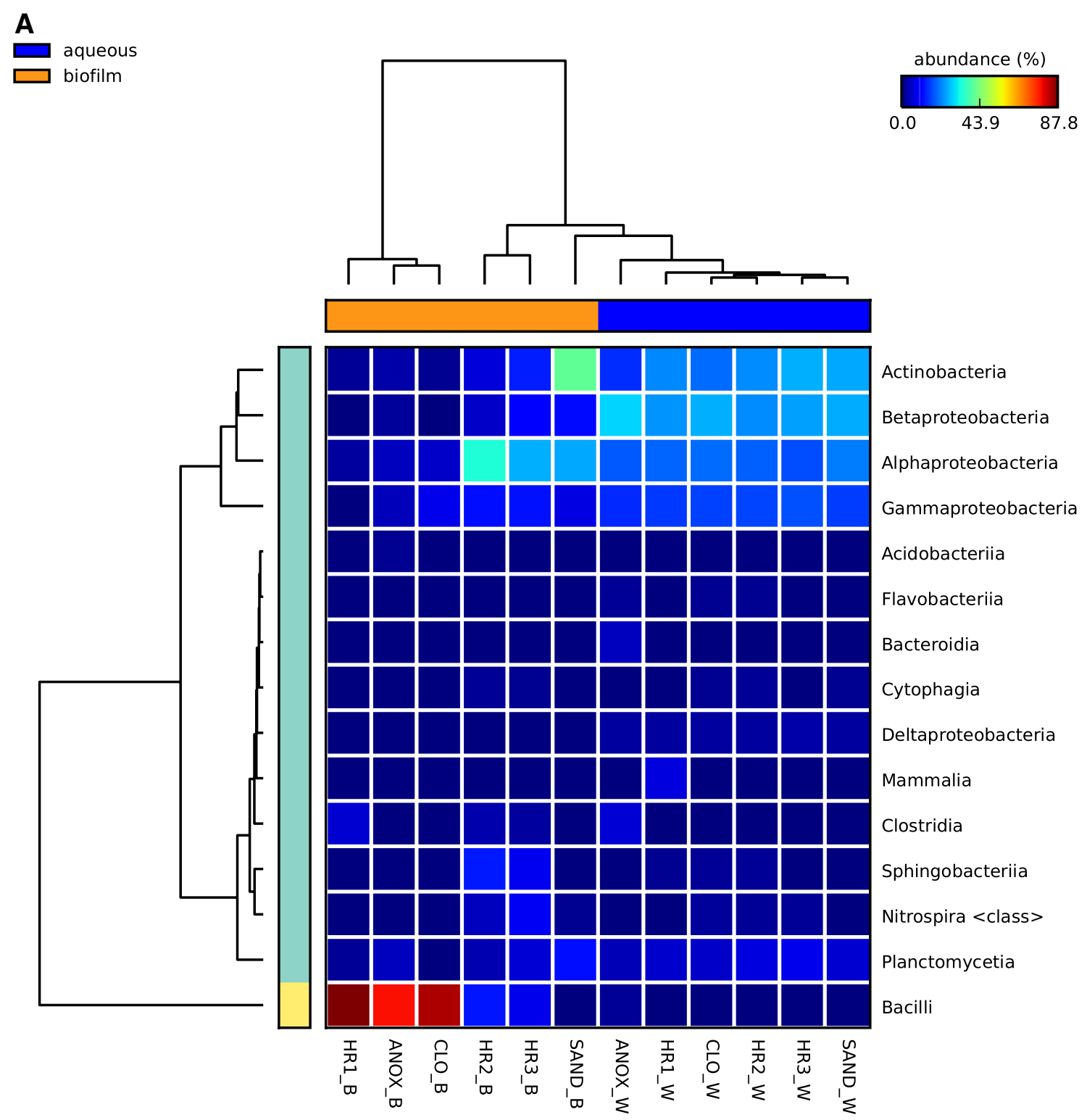

B

$95 \%$ confidence intervals

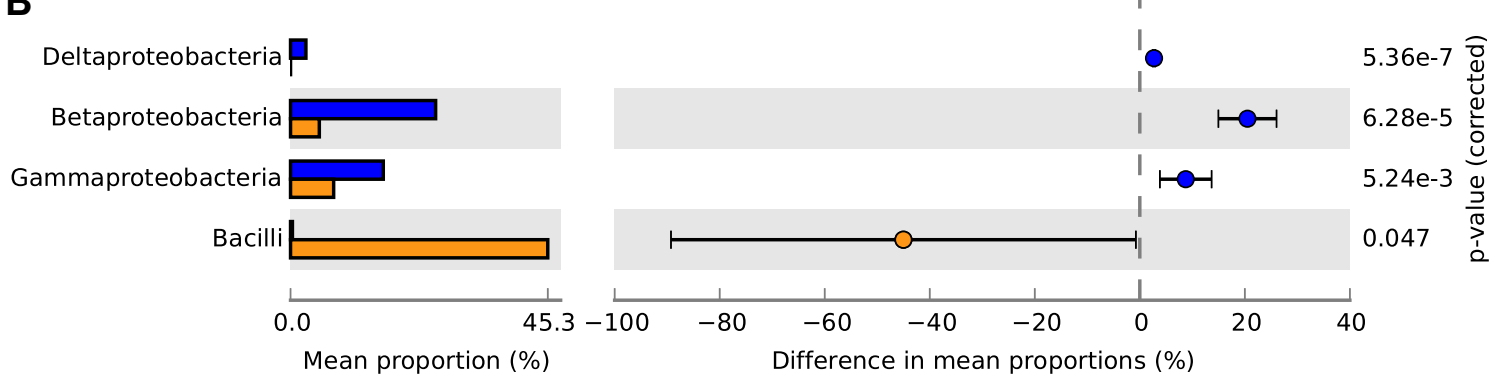

Figure 5. Relative abundance of microbial classes in the ecological wastewater treatment plant. A. Heat map depicting the relative abundance of microbial taxonomic classes identified in the different aqueous and biofilm phases in each treatment tank of the ecological wastewater treatment plant. B. Differences in mean proportions of major microbial taxonomic classes identified collectively in the aqueous and biofilm phases of the ecological wastewater treatment plant. Statistical Analysis of Metagenomic Profiles (STAMP) software v2.1.3. Abbreviations: W - aqueous, B - immersed biofilm, ANOX - anoxic tank, CLO - closed aerobic tank, HR1, HR2 and HR3 - planted aerobic tanks, and SAND - sand filter. 


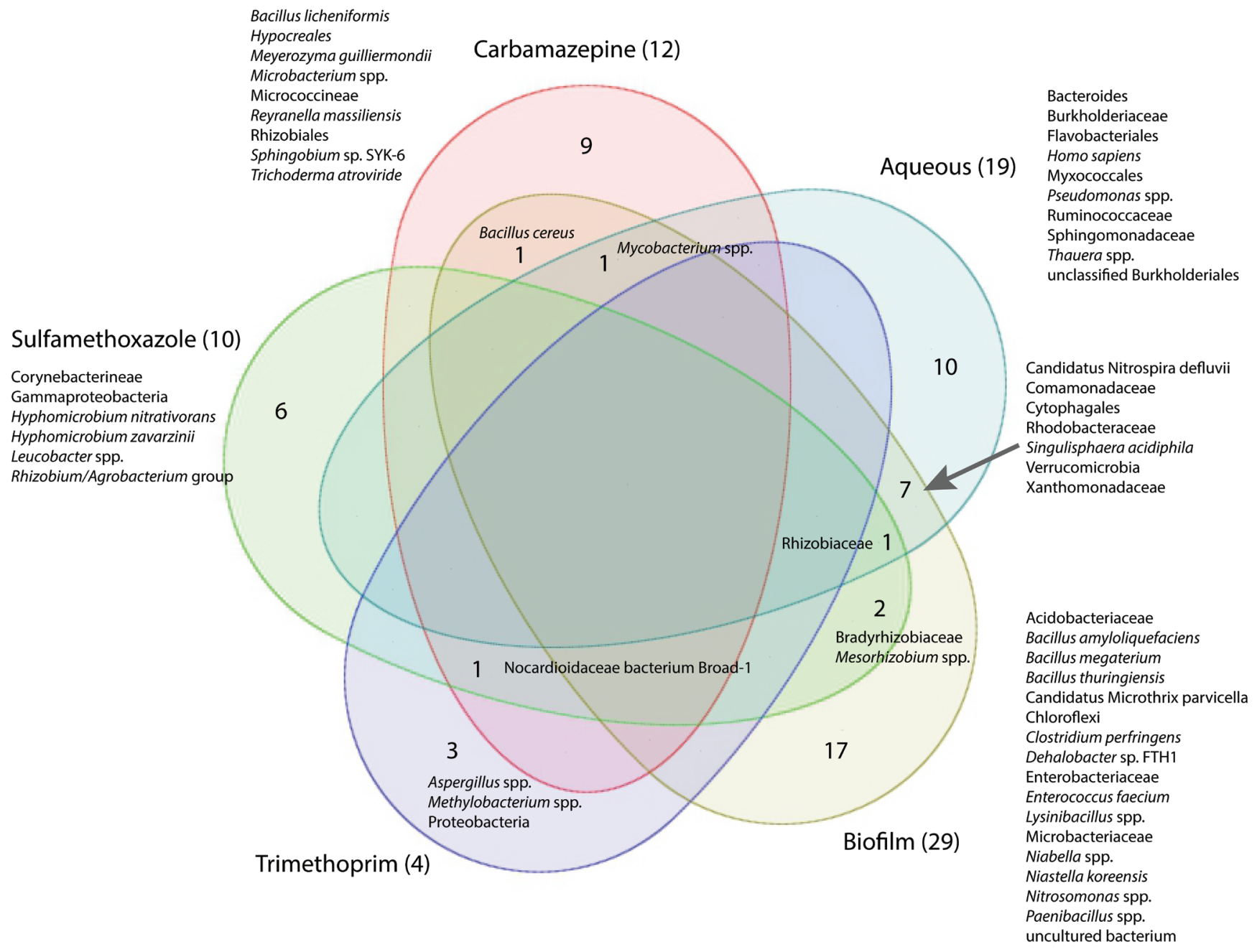

Figure 6. Co-occurrence of microbial taxa in the aqueous, biofilm, and pharmaceutical enrichment cultures. Venn diagram illustrating sequences with taxonomic identities retrieved from the aqueous and biofilm samples obtained from the ecological wastewater treatment plant and the carbamazepine, sulfamethoxazole and trimethoprim aqueous enrichment cultures. Numbers in parentheses after sample set names indicate taxa identified to species level in each metagenome sequence dataset. Numbers within the diagram indicate taxa common to the individual and overlapping datasets. (Partek ${ }^{\circledR}$ Genomics Suite ${ }^{\circledR}$ software, version 6.6 build 6.15.1016 Copyright 2014; Partek Inc., St. Louis, MO, USA)

To assess the influence of the carbon sources on enrichment culture taxonomic composition, LCA-based taxonomic profiles of the enrichment culture replicates were compared in STAMP. The most numerous significant differences with strong effect sizes were found at the family level (see supplementary material ST35). The relative abundance of reads from Bradyrhizobiaceae, Hyphomicrobiaceae, Microbacteriaceae, and Rhizobiaceae were significantly greater in sulfamethoxazole cultures than in trimethoprim or carbamazepine cultures (with FDR corrected p-values of $2.98 \times 10^{-8}, 0.0274,0.0199,0.381$, respectively).

\section{Microbial metabolism of PPCPs}

To investigate the role of the WWTP's microbial communities in the metabolism of PPCPs, KEGG was queried using MEGAN for sequences identified as involved in xenobiotic metabolism. Figure 7 depicts the percent relative abundances of sequences identified in the metagenomes obtained from each sample as involved in xenobiotic biodegradation and metabolism KEGG pathways for WWTP samples. The most abundant xenobiotic biodegradation and metabolism subcategory in all cultures and WWTP samples, with a few exceptions (HR1_B, C3B and C3D), was benzoate degradation comprising $14.5 \%-17.7 \%$ of reads in this subcategory for WWTP samples and $11.1 \%-23.6 \%$ in the enrichment culture samples. The biofilm sample obtained from the sand filter (Sand_B) at the end of the WWTP treatment train produced the greatest number of sequences $(18,766)$ aligning to the "xenobiotic biodegradation and metabolism" category in the KEGG database followed by the aqueous samples of the sand filter (SAND_W) $(18,318)$, and the 

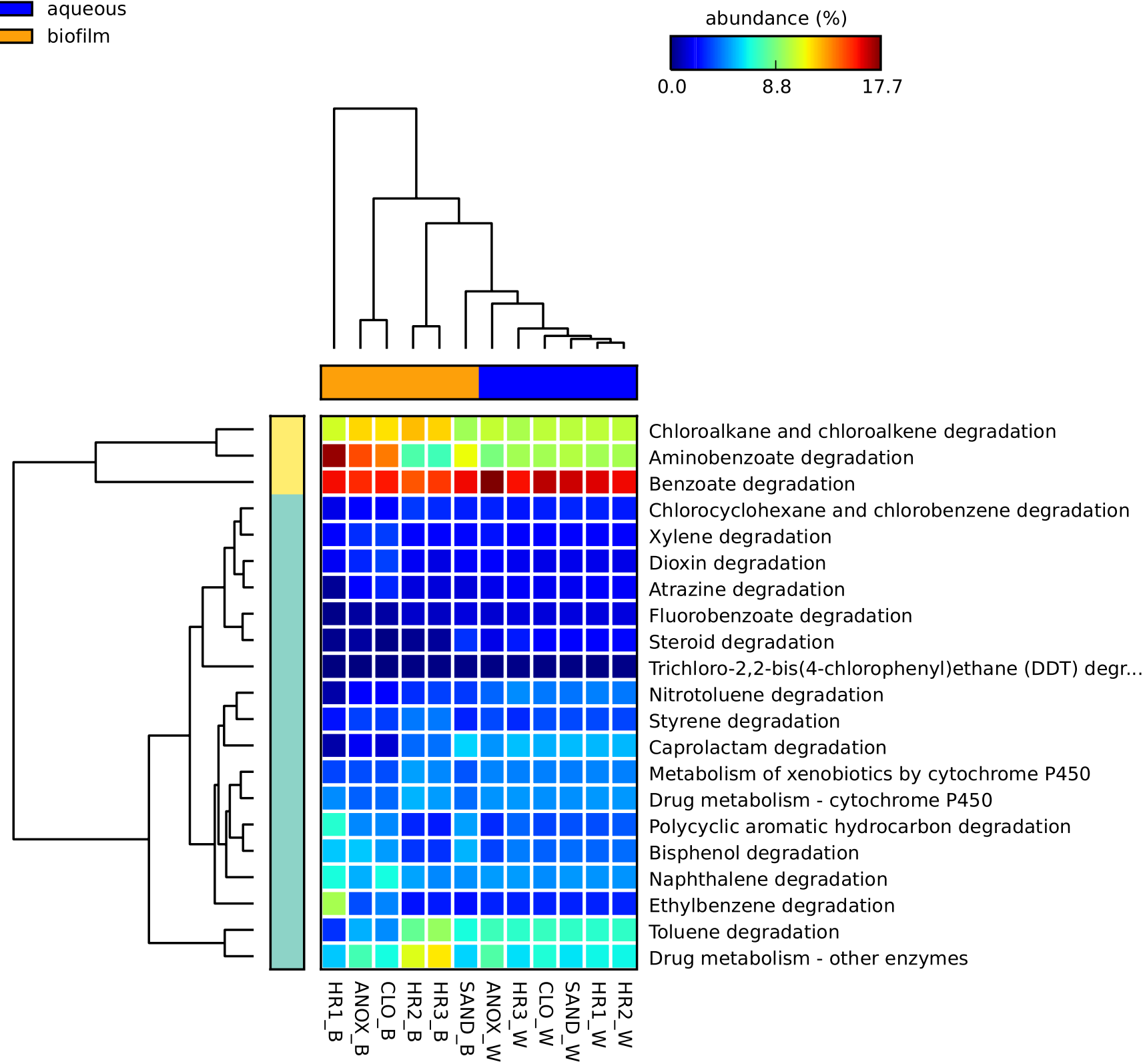

Figure 7. Relative abundance of xenobiotic metabolism genes identified in the microbial communities of the ecological wastewater treatment plant. Heat map indicating the relative number of sequence reads associated with the KEGG xenobiotic metabolism categories (on right) identified in each sample location and phase (on bottom). Statistical Analysis of Metagenomic Profiles (STAMP) software v2.1.3. Abbreviations: W - aqueous, B - immersed biofilm, ANOX - anoxic tank, CLO - closed aerobic tank, HR1, HR2 and HR3 - planted aerobic tanks, and SAND - sand filter.

aqueous phase of the third planted aerobic tank (HR3_W) (18,002). The sample with the greatest number of reads associated with KEGG pathway "drug metabolism-cytochrome P450" was the aqueous phase of the third planted aerobic tank (HR3_W) $(1,384)$ followed by aqueous samples of the sand filter (SAND_W) $(1,372)$ and the immersed biofilm sample obtained from the first planted aerobic tank (HR1_W) $(1,330)$. The sample with the greatest number of reads associated with the KEGG category "drug metabolism - other enzymes" was the biofilm in the second planted aerobic tank (HR2_B) $(2,181)$ followed by aqueous phase of the anoxic tank (ANOX_W) $(1,904)$, and the biofilm sampled from the sand filter (SAND_B) $(1,827)$.

The percent relative abundances of xenobiotic metabolism-associated sequences identified in enrichment cultures' metagenomes are illustrated as a heat map in Figure 8 (see Supplementary materials ST6). Reads associated with benzoate degradation were most abundant for trimethoprim cultures, whereas chloroalkane and chloroalkene degradation reads were most abundant 
trimethoprim

sulfamethoxazole

carbamazepine
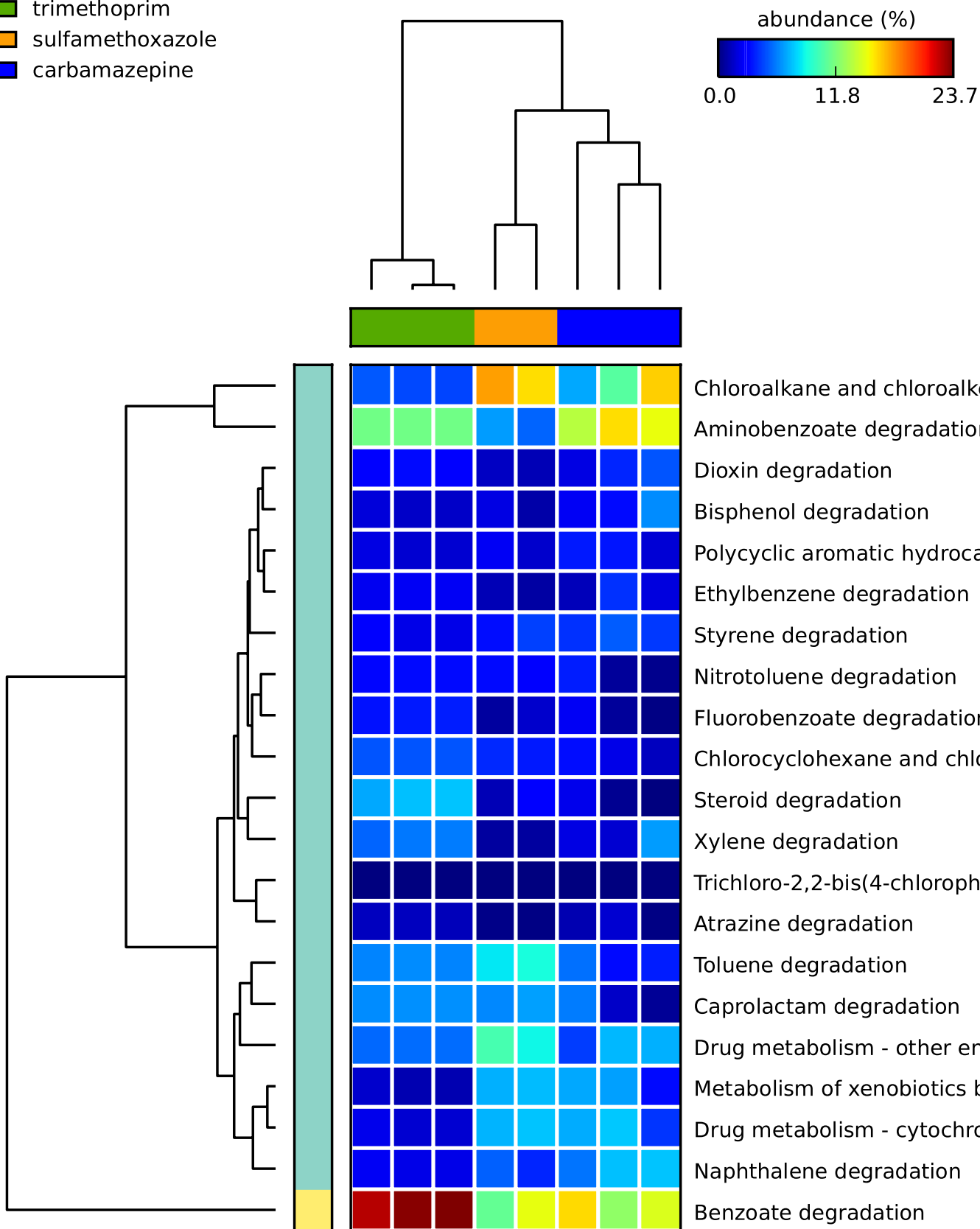

Chloroalkane and chloroalkene degradation Aminobenzoate degradation

Dioxin degradation

Bisphenol degradation

Polycyclic aromatic hydrocarbon degradation

Ethylbenzene degradation

Styrene degradation

Nitrotoluene degradation

Fluorobenzoate degradation

Chlorocyclohexane and chlorobenzene degradation

Steroid degradation

Xylene degradation

Trichloro-2,2-bis(4-chlorophenyl)ethane (DDT) degr...

Atrazine degradation

Toluene degradation

Caprolactam degradation

Drug metabolism - other enzymes

Metabolism of xenobiotics by cytochrome P450

Drug metabolism - cytochrome P450

Naphthalene degradation

Benzoate degradation

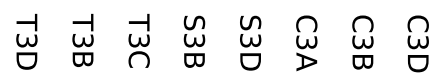

Figure 8. Relative abundance of xenobiotic metabolism genes identified in the pharmaceutical enrichment cultures. Heat map indicating the relative number of sequence reads associated with the KEGG xenobiotic metabolism categories (on right) identified in each pharmaceutical compound carbon source enrichment culture sample (on bottom). Samples starting with C, T, and S indicate metagenomes isolated from cultures grown on carbamazepine, trimethoprim, and sulfamethoxazole carbon sources, respectively. Statistical Analysis of Metagenomic Profiles (STAMP) software v2.1.3. 


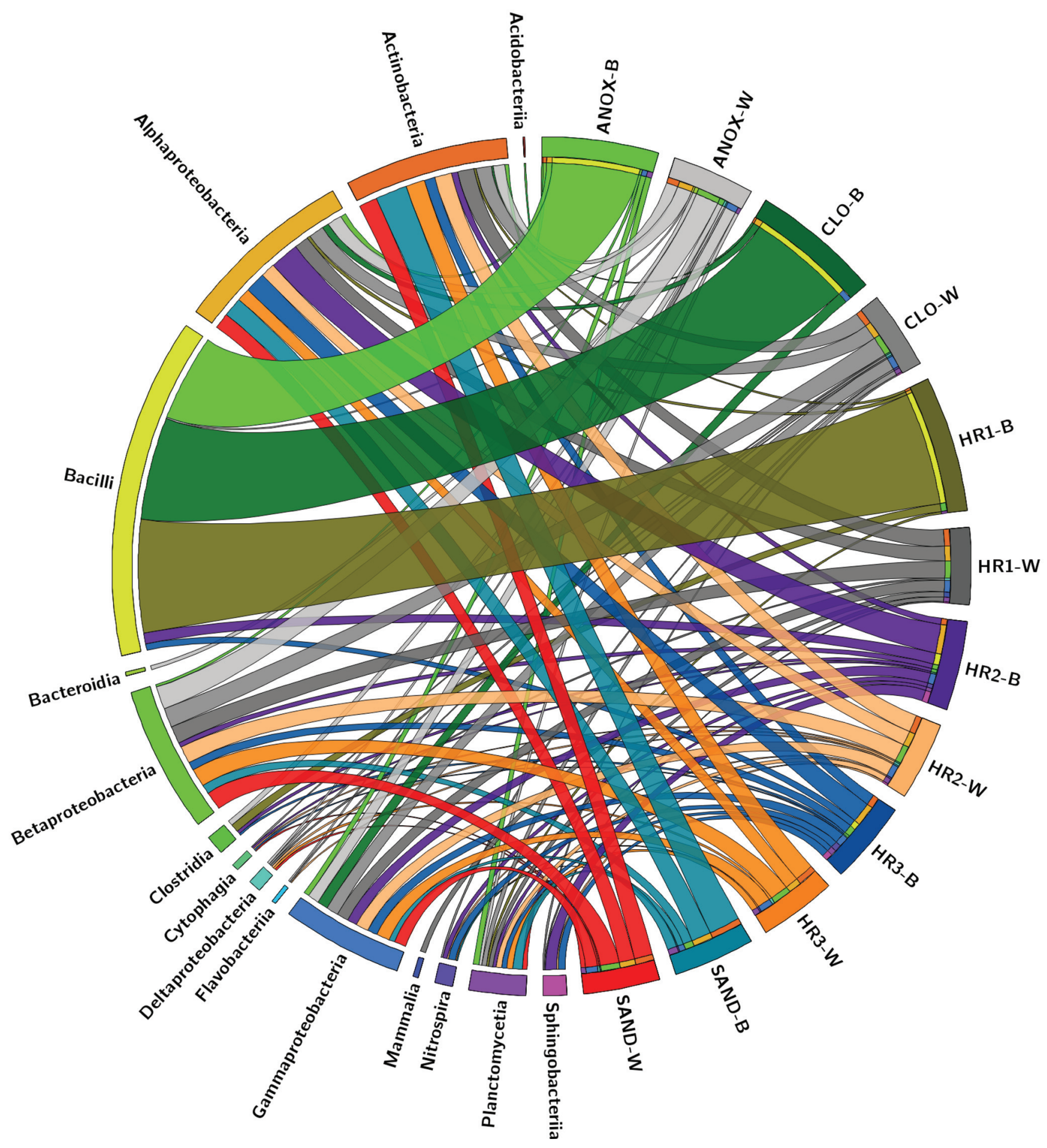

Figure 9. Location and relative abundance of microbial taxonomic classes identified in the two different phases of the ecological wastewater treatment plant. Relative abundances of microbial class-level taxa identified in the metagenomes isolated from the biofilm and wastewater phases of each treatment tank of the ecological wastewater treatment system. The relative abundance of each class in each sample is represented in the width of each ribbon. The clockwise order of the samples is represents the order of the wastewater treatment process. Circos software v0.69. Abbreviations: ANOX- anoxic tank, CLO- closed aerobic tank, HR1, HR2 and HR3- planted aerobic tanks, and SAND - Sand Filter. 
for sulfamethoxazole cultures. The most abundant xenobiotic metabolism category for the carbamazepine cultures varied from culture to culture with aminobenzoate degradation, benzoate degradation, and chloroalkane/chloroalkene degradation categories for each of the three replicates. The samples $\mathrm{C} 3 \mathrm{~A}$ and T3D produced the greatest number of reads associated collectively with xenobiotic metabolism genes at 232, 201 and 218, 591, respectively. Of these, C3A and T3D metagenomes contained 10,151 and 11,889 reads associated with "drug metabolism - other enzymes" in KEGG, respectively. In this category, the sulfamethoxazole culture (S3B and S3D) had the most assigned reads at 16,102 and 13,730, respectively. For the category "Drug metabolism - cytochrome P450" the carbamazepine culture sample C3A contained the greatest relative number of sequences $(16,199)$ followed by the sulfamethoxazole culture S3D $(11,847)$.

\section{Discussion}

To our knowledge, this is the first study to use WMS to characterize the microbial communities of an ecological WWTP. While a taxonomic description of the microbial communities is provided, here we have focused on microbial metabolism of PPCPs in the wastewater. Using WMS we have identified representation and relative abundance of microorganisms in the six major treatment tanks. To examine the role plants have on the structure of the microbial communities, we compared the communities found in the wastewater and those attached to plant roots immersed in the wastewater. Microbial metabolic pathways for most emerging pollutants, including micropollutants such as PPCPs, have not been characterized. Therefore, we have focused on the xenobiotic metabolic capacity as represented by the location and abundance of known genes represented in the KEGG database.

\section{PPCPs in the wastewater}

The concentrations of PPCPs in the samples obtained from the Sharon, VT WWTP indicate that some of the PPCPs are being effectively removed by the system (naproxen and thiabendazole), while others are accumulating in the recirculating system (caffeine, carbamazepine, DEET, trimethoprim, and sulfamethoxazole) (Table 1). The increasing concentrations of caffeine, gemfribozil and ibuprofen in or after the sand filter suggest partitioning to the aqueous phase from attenuated organic matter may be occurring in the sand filter. However, based on these data, biotic (biodegradation) and abiotic (partitioning to the primary sewage sludge) processes occurring in the influent holding tank and first treatment tank (ANOX) account for significant reductions in concentrations for the PPCPs gemfibrozil, naproxen, thiabendazole, and to a lesser degree caffeine, ibuprofen, sulfamethoxazole, whereas carbamazepine, DEET, and trimethoprim were not removed.

Partitioning to the solid phase (sewage sludge) is an important aqueous phase removal processes that is driven by a compound's hydrophobicity ${ }^{44,45}$. For certain chlorinated organic compounds, the octanol-water partitioning coefficient $\left(\mathrm{K}_{\mathrm{ow}}\right)$ correlates positively with sorption to biosolids when $\log \mathrm{K}_{\mathrm{OW}}$ values range from 1.26 to $5.48^{46}$. Carbamazepine $\left(\log \mathrm{K}_{\mathrm{OW}} 2.3-2.5\right)$, DEET $\left(\log \mathrm{K}_{\mathrm{OW}} 2.18-\right.$ $2.44)$, and trimethoprim $\left(\log \mathrm{K}_{\mathrm{OW}} 0.9-1.4\right)$ show limited removal in the Sharon, VT WWTP (Table 1). These findings are consistent with similar studies on partitioning of PPCP in conventional
WWTP $^{47-49}$. Partitioning rates from aqueous influent to biosolids (sewage sludge) is variable with $\log \mathrm{K}_{\mathrm{d}}$ (solid-water distribution) values ranging from $<0.7$ to $4.2^{50}$ depending on the compound. The removal of the parasiticide, fungicide thiabendazole $\left(\log \mathrm{K}_{\mathrm{OW}}\right.$ 2.47) from the wastewater between the influent sample location and the anoxic treatment tank was likely due to strong partitioning to the primary sludge in the holding tank. With this exception, all other compounds were detected in more than one tank of the system. The aqueous concentrations of the cholesterol-lowering drug gemfribozil ( $\log \mathrm{K}_{\mathrm{OW}} 4.77$ ) also indicated strong partitioning to the primary sludge showing reduction in concentration by three orders of magnitude between the influent and the anoxic treatment tank.

Pharmaceuticals and PPCPs in wastewater can undergo a number of processes that contribute to their complete or partial aqueous phase removal in wastewater treatment systems ${ }^{45}$. These include chemical and or physical processes such as sorption to organic matter $^{46,48,51}$, photolysis $^{52,53}$, volatilization ${ }^{50}$, and biological transformation ${ }^{54}$. Biological transformation is unique among these as it provides WWTP operators the potential to increase the removal of PPCPs from wastewater while partially or completely mineralizing the compounds thereby eliminating any risks associated with their release to the environment. In contrast, sorption to biomass (primarily sewage sludge) results in decreased mineralization $^{55}$, which when applied to land (dominant disposal method of the processed sewage sludge) is likely a significant source of PPCPs in the environment ${ }^{56}$. It is unclear whether thermal treatment and dewatering, as is commonly done to biosolids prior to land application, alters the mass of PPCPs in this media.

The influent concentrations of the PPCPs were in many cases an order of magnitude or greater than the concentrations reported in conventional WWTP ${ }^{49,57}$. The Sharon, VT ecological WWTP recirculates the effluent onsite as flush water (sterilized and dyed blue prior to being used as toilet and urinal flush-water). The recirculation and reuse of the effluent is likely to result in an additive or concentrating effect for compounds with low removal and/or partitioning rates. Additionally, the concentration of PPCPs in municipal wastewater is likely diluted by the mixing of non-human wastewater such as wash water, storm water (in combined sewer systems), industrial process water and a variety of other sources. While the higher concentration of PPCPs in this recirculating ecological WWTP may present elevated exposure risks to operators and the environment if materials are discharged, conventional WWTP, which do not recirculate wastewater, are likely to discharge greater mass of PPCPs per liter wastewater treated. Additionally, retaining the PPCPs in the WWTP through recirculation is preferential to releasing them into receiving water bodies.

The results reported here are initial findings on the removal of PPCPs from the wastewater processed by this system as the species and concentrations of detected PPCPs are likely to change with time, fluctuating with the changing population of visitors. Significant variability in PPCPs species and mass loading into the system is likely responsible for the non-detects (Table 1 ND's) of individual compounds detected later in the treatment train. As we staggered our sampling of the initial three and latter three treatment tanks by 48 hours to accommodate the residence time of the 
wastewater in the treatment system, it is reasonable to assume that the concentrations quantified here represent the flux of PPCPs through the WWTP. Therefore, changes in the concentration of individual PPCPs throughout the system are the result of biotic and abiotic aqueous phase removal processes. The trends observed here could be influenced by fluctuations in PPCPs inputs. These fluctuations are likely responsible for the non-detects observed in the holding tank (INF) for carbamazepine, DEET and trimethoprim, while these compounds were detected in the next treatment tank (ANOX).

\section{Microbial communities of the ecological WWTP}

The immersed biofilm and aqueous phase microbial communities exhibited two distinct taxonomic structures. According to the LCA algorithm, this difference was most evident at the class level (Figure 5a). The relative abundances of Deltaproteobacteria, Betaproteobacteria, and Gammaproteobacteria were significantly higher in the microbial metagenomes of the aqueous phase, while Bacilli were observed in greater abundance in the immersed biofilm microbial communities (Figure 5b). The relative abundance of Bacilli in the immersed biofilm communities was highly variable, with their dominance diminishing significantly after the first three tanks. Figure 9 illustrates the microbial taxonomic spatial variability of the ecological WWTP. The sample order in the diagram reflects wastewater movement through the treatment system starting with the anoxic tank (ANOX) moving clockwise to the sand filter (SAND). The width of each ribbon extending from the taxon to the sample represents relative abundance based on sequence counts. Bacilli dominated the immersed biofilm in the first three tanks (ANOX, CLO, and HR1), with representatives of other taxa present to a much lesser degree. The immersed biofilm samples also show greater microbial taxonomic richness in the latter phases of the treatment system (HR2, HR3, and SAND). This pattern is likely due to retention of fecal taxa by the earlier tanks as Bacilli are known to be abundant in human feces ${ }^{43}$. Bacteroidia, which is also abundant in human feces ${ }^{58}$, was not detected colonizing the immersed plant root surfaces. Only a small population was identified in the wastewater obtained from the anoxic tank.

Members of the Firmicutes (Bacilli) and Bacterioidia, which are common in human feces ${ }^{58}$, were identified in the ecological WWTP microbial communities. However, these were the only organisms identified in the samples that are associated with human feces. Of the organisms used in water quality criteria to indicate contamination by feces (others include Clostridium perfringens, enterococci, Escherichia coli, and fecal coliforms), Clostridium perfringens was detected in only one sample, HR1_B (Figure 2). This would indicate that the ecological WWTP is performing well with regard to attenuating fecal coliforms. Bacilli were dominant in the samples of immersed biofilm collected from the first three tanks in contrast to the taxonomic composition of the latter three treatment tanks (Figure 2, Figure 9). This could indicate colonization of the surfaces in these initial treatment tanks by organisms of fecal origin. The wastewater samples from these tanks as well as biofilm samples collected from tanks later in the treatment train did not show this pattern (Figure 9).

The microbial taxonomic composition of the immersed biofilm in the downstream tanks increased in richness with Actinobacteria,
Alphaproteobacteria, Bacilli, Gammaproteobacteria, Sphingobacteria and to a lesser degree Betaproteobacteria, and Planctomycetia identified by LCA. This is in contrast to the aqueous phase microbial community, which showed taxonomically rich populations throughout the system with members of the Actinobacteria, Betaproteobacteria, Alphaproteobacteria, and Gammaproteobacteria in greatest abundance (Figure 9).

The taxonomic composition of the microbial communities forming biofilm on the plant root surfaces immersed in the wastewater changed significantly over the course of the wastewater treatment process. The taxonomic dissimilarity (Figure 4) observed among the immersed plant root biofilm samples showed three distinct communities: The anoxic (ANOX_B) and the closed aerobic (CLO_B); the first planted aerobic (HR1_B); the second and third planted aerobic tanks (HR2_B and HR3_B); and the sand filter (SAND_B). The changing characteristics of the first tanks of the treatment system (anoxic to aerobic conditions) is likely driving a transition from anaerobes such as Bacteriodes, and facultative anaerobes or microaerophiles such as Bacillus, Clostridium, Nocardia, Mycobacterium, to aerobic communities. The abundance of the facultative anaerobe group, Bacilli is likely promoted by the oxygen limiting environment in the first two tanks ${ }^{43}$. The immersed biofilm microbial community of the first planted aerobic tank (HR1) is taxonomically distinct from HR2 and HR3 despite identical physiochemical conditions. This pattern may be influenced by the composition of plant species in the individual tanks, which varies from tank to tank, or perhaps the diminishing influence of organisms contributed by feces.

There is limited ability to relate the results of our analysis of the microbial communities of this ecological WWTP to that of other systems serving different populations and geographic locations as this appears to be the first published findings on the topic. However, metagenomic analyses of the microbial ecology of conventional (activated sludge) wastewater systems have been described elsewhere ${ }^{59-62}$.

For example, Lee et al., $2014^{59}$ employed 16S rRNA gene microarrays (PhyloChip) to establish a baseline microbial community structure of the municipal WWTP aeration basin. The microbial taxonomic composition of the aeration basin showed some similarities with that of the entire ecological WWTP sampled here. Specifically, Proteobacteria and Firmicutes were abundant in both the conventional system and ecological WWTP sampled here. To assess the microbial community seasonal variation of activated sludge over a four-year period Ju et al., 2014 $4^{63}$ employed WMS, as was used here. They showed variation in microbial taxonomic composition between the summer and winter samples. They also found variation in the microbial community composition over the four years sampled, irrespective of season. The metabolic structure of activated sludge according to SEED subgroups appeared to remain stable, in spite of variation in taxonomic composition, which suggests microbial community functional redundancy may be present in these systems. The ecological WWTP sampled for this work is housed in a climate-controlled glass house, which raises questions as to whether the microbial community varies from year to year and season to season. The microbial communities are not likely to exhibit temperature-dependent seasonal variation. Taxonomic variation may occur as a result of changes in the microbial communities contributed by the visitors. 
The role plants have on influencing the structure of the rootcolonizing microbial communities appeared to increase after the first three treatment tanks. The attenuation of taxa contributed by feces (Bacillus) after the first three treatment tanks is reflected in the increased microbial taxonomic heterogeneity in the latter two planted aerobic tanks (HR2 and HR3), which is reflected in the branch lengths for these samples in the neighbor joining network shown in Figure 4. These results indicate the need to design ecological WWTPs with sufficient retention time to allow for the attenuation of stool microbial communities and the development of diverse microbial biofilm communities.

\section{Removal of PPCPs by the ecological WWTP}

The dominant PPCP removal process from the wastewater appears to be partitioning to sludge (biosolids) and biodegradation under nitrifying conditions, which are both reflected in the reductions in aqueous PPCP concentrations that occurred early in the treatment process. Primary sludge settles out of the wastewater in the holding tank and is periodically removed for off-site disposal. The concentration of some of the detected PPCPs continued to decline as the wastewater continued through the system (Table 1) indicating some continued removal beyond the first two or three tanks. For example, while the concentration of caffeine declined between the holding $\operatorname{tank}\left(9.5 \times 10^{4} \mathrm{ng} \mathrm{L}^{-1}\right)$ and the anoxic tank $\left(1.9 \times 10^{4} \mathrm{ng} \mathrm{L}^{-1}\right)$, further reduction from the aqueous phase was observed in the subsequent three aerobic treatment tanks (CLO, HR1, HR2). Given that caffeine is a hydrophilic organic base (low $\mathrm{K}_{\mathrm{Ow}}$ ) only moderate partitioning to sludge is expected (86) and microbial biodegradation is likely to be responsible for the reduction in caffeine concentrations observed from the aerobic treatment tanks. Ibuprofen concentrations followed a pattern similar to caffeine's in that significant reductions were seen in the first three aerobic treatment tanks $\left(1.1 \times 10^{4} \mathrm{ng} \mathrm{L}^{-1}\right.$ to $\left.5.6 \times 10^{2} \mathrm{ng} \mathrm{L}^{-1}\right)$. Carbamazepine, DEET, and trimethoprim concentrations remained stable throughout the treatment process. The combination of low partition to primary sludge expected and metabolic recalcitrance accounts for their stability in system ${ }^{47,50,55}$.

Microbial biodegradation pathways for most PPCPs have not been characterized, which makes it difficult to directly detect responsible genes. Nevertheless, ammonia oxidizing bacteria have been associated with the biodegradation of some PPCPs, while others have been shown to be degraded by nitrite oxidizing bacteria $^{64,65}$. The relative abundances of sequences that MEGAN associated with ammonia monooxygenases were very low throughout the system (ranging from 0 to 53 reads), but were highest in the biofilm samples obtained from the HR3 and HR2 tanks. Due to lower dissolved oxygen levels, genes involved in denitrification (nitrite reductases) were found to be in highest relative abundance in the anoxic (ANOX) and closed (CLO) tanks (644 and 688 , respectively).

Functional attributes of detected taxa reported in the literature can be used to identify metabolic potential pertinent to uncharacterized xenobiotic metabolic pathways. For example, in the first three tanks, the Firmicutes colonizing plant root surfaces have been reported to metabolize xenobiotics. Bacillus cereus, B. megaterium and $B$. amyloliquefaciens have been reported to metabolize phenol $^{66}$, crude oil ${ }^{67}$, textile dyes ${ }^{68}$, and other xenobiotics through the induction of cytochrome P450s $\mathrm{s}^{69,70}$. Dehalobacter sp. FTH1, identified in the plant root biofilm sample obtained from the second planted aerobic tank (HR2), has been reported to dechlorinate a number of organohalide xenobiotics ${ }^{71,72}$. Clostridium, identified in the root biofilm sample obtained from the first aerobic tank (HR1), has been reported to be involved in metabolism of bromophenols as a member of a consortium including Delhalobater $^{73}$. Entercoccus spp., identified in the plant root biofilm of HR2, has been reported to degrade azo dyes ${ }^{74}$.

Of the Actinomycetales identified, Mycobacterium spp., which have been reported to metabolize a variety of xenobiotics including polycyclic aromatic hydrocarbons ${ }^{75}$, biphenyls ${ }^{76}$, as well as various pharmaceuticals ${ }^{77}$ were identified in low relative abundance in samples obtained from the biofilm growing on plant roots in the anoxic tank and in high relative abundance in the biofilm sampled from sand filter. Mycobacterium spp. was also identified in the aqueous wastewater throughout the system (Figure $2 \&$ Figure 9). While this metabolically plastic genus has been reported to be capable of metabolizing a wide variety of xenobiotics it should be noted that there are numerous pathogenic taxa including M. tuberculosis, M. bovis, and M. avium among others. The biofilm sample obtained from the sand filter contained 10,282 reads associated with human diseases and 18,766 reads associated with xenobiotic metabolism by the LCA algorithm in MEGAN.

Rhizobiales, which were identified in the aqueous phase throughout the system as well as in the biofilm sampled in the latter three treatment tanks (HR2, HR3, and SAND) have been reported as abundant in biofilm reactors treating sulfamethoxazole containing wastewater ${ }^{78}$. Also present throughout the system's aqueous phase were members of the Rhodobacteraceae, Burkholderiaceae, Comamonadaceae, Pseudomonas, and Xanthomonadaceae, which have been reported to metabolize aromatic hydrocarbons ${ }^{79,80}$. Among these, the genus Pseudomonas has been identified as capable of biodegradation a variety of xenobiotic including some pharmaceuticals in a number of other settings including membrane bioreactors ${ }^{81}$, cultures originating from pharmaceutical wastewaters $^{82}$, and environmental samples ${ }^{83}$.

Greater xenobiotic metabolic heterogeneity was observed in the samples obtained from the plant root-associated biofilm as compared to the free-floating aqueous microbial community. The aqueous microbial metagenome, collectively, contained a greater total for xenobiotic metabolism gene copies $\left(1.2 \times 10^{5}\right.$ compared to $8.6 \times 10^{4}$ for the plant root biofilm) (see Supplementary material ST5). When comparing the proportion of sequences identified in the aqueous and biofilm phases of the system, which represent the non-root-associated and root-associated microbial populations, respectively, the xenobiotic metabolism gene categories nitrotoluene, benzoate, flurobenzoate and steroid degradation were found to be significantly higher in the aqueous phase samples (Welch's t-test p-values < 0.05) (see Supplementary material ST49) (Figure 7). However, when comparing the type and abundance of reads associated with xenobiotic metabolism (KEGG level 3) the aqueous phase samples all resembled one another whereas, the biofilm samples were heterogeneous (see Figure 7 and Supplementary material ST31). 
For aqueous phase microbial communities, growth of microbial consortia with the capacity to metabolize a given PPCP is driven by the presence of the compound in the wastewater, which will fluctuate with time. Stationary biofilm communities are likely to be more stable populations. These communities can accumulate with time and potentially acquire metabolic genes by horizontal gene transfer ${ }^{84}$. In contrast to the aqueous phase xenobiotic metabolism, which was dominated by benzoate degradation genes, the plant root microbial biofilm metagenomes contained higher relative abundances of other categories including aminobenzoate, chloroalkane/chloroalkene, and to a lesser degree ethylbenzene categories (Figure 7). However, of these categories, only chloroalakane/ chloroalkene was significantly higher (Welches t-test p-value 0.031) in the biofilm samples collectively (see Supplementary material ST49).

While others have identified ammonia oxygenases and nitrite reductases as being involved in microbial PPCP biodegradation ${ }^{64}$, the relative abundances of these gene categories were very low throughout the system. The relative abundance of xenobiotic metabolism gene copies was highest for the sand filter samples at 18,318 for SAND_W and 18,766 for SAND_B (see Supplementary material ST30). The sand filter's ability to attenuate and accumulate sloughed off microbial cells as the wastewater passes through may be driving an accumulation of microbial biomass. If this is the case, sand filters are likely to have populations of the microbial communities found throughout the aqueous phase of the system, yet may not serve as a location of high metabolic activity, thereby contributing little to the metabolism of xenobiotics. The increase in concentrations observed for some of the PPCPs (caffeine, carbamazepine, DEET, gemfribozil, and ibuprofen) after the wastewater passed through the sand filter, if a real trend, could support this perspective.

Culture bias was reflected in the taxonomic composition of the enrichment cultures growing on the sole pharmaceutical carbon sources examined here. While culture bias is well known ${ }^{85}$ and was expected, the enrichment of organisms capable of metabolizing individual pharmaceutical compounds from the WWTP effluent water reflects the ability for the ecological WWTP to support this metabolic capability. Only one taxon (Bacillus cereus) was identified in at least one enrichment culture (carbamazepine) and the biofilm sampled from the WWTP and one taxon (Mycobacterium spp.) was identified in the aqueous, biofilm and carbamazepine enrichment cultures (Figure 6). Given the selective pressure supplied by culturing, it is unlikely that these two taxa are solely responsible for the biodegradation of carbamazepine in the ecological WWTP. However, having isolated pharmaceutical metabolizing consortia from effluent water suggests the ecological WWTP supports microbial populations with the capacity remove recalcitrant micropollutants from wastewater.

Secondary plant metabolites contributed to the wastewater by the tropical species cultivated in planted tanks may help support populations of microbial communities with xenobiotic degradation capabilities by providing a more consistent supply of structurally diverse carbon sources. The most abundant category of xenobiotic metabolism genes was associated with benzoate degradation in nearly all the samples. Benzoate degradation is known to play a role in the degradation of a variety of aromatic compounds ${ }^{23,86,87}$. The dominance of this functional category suggests that microbial communities in the aqueous phase were metabolizing a variety of benzoate-containing compounds, which were likely to include metabolites of plant and xenobiotic origin. However, further work is needed to determine whether plant-microbe feedback processes promote PPCP biodegradation in ecological WWTPs.

\section{Data availability}

FASTQ files and associated metadata are available at NCBI BioProject ID PRJNA286671 (http://www.ncbi.nlm.nih.gov/bioproject/286671).

\section{Author contributions}

IB conceived of the study, designed the experiments and was awarded the funding that supported the work. HD contributed to the statistical and bioinformatics analysis. JV developed and refined the bioinformatics workflow as well as contributed bioinformatics analysis. ML created the enrichment cultures as a part of her senior thesis project. IB prepared the first full draft of the manuscript. IB and HD prepared the manuscript revisions. JV was involved in the revisions of the draft manuscript. All authors have contributed to and agreed to the final content of the manuscript.

\section{Competing interests}

The authors have no competing interests to declare.

\section{Grant information}

Research reported in this publication was supported by an Institutional Development Award (IDeA) from the National Institute of General Medical Sciences (NIGMS) of the National Institutes of Health (NIH) under grant number P20GM103449 awarded to INB through the Vermont Genetics Network (VGN). Its contents are solely the responsibility of the authors and do not necessarily represent the official views of NIGMS or NIH.

The funders had no role in study design, data collection and analysis, decision to publish, or preparation of the manuscript.

\section{Acknowledgements}

We would like to acknowledge VGN for their efforts to promote research at undergraduate institutions. Timothy Hunter and Scott Tighe at the University of Vermont Advanced Genome Technologies Core (AGTC) developed and refined the protocol for, and completed, the genomic DNA extractions. Brewster Kingham at the University of Delaware, DNA Sequencing \& Genotyping Center, Delaware Biotechnology Institute provided DNA sequencing. Finally, INB would like to acknowledge the guidance and feedback from Mary Tierney at the University of Vermont, Plant Biology Department and John Todd of Todd Ecological Design. INB would also like to acknowledge the numerous Lyndon State College undergraduate students that have contributed to this work through course work and senior thesis research. The authors are listed in the order of their contribution to this study. 


\section{Supplementary material}

Data tables ST1-49

Click here to access the data.

Figures S1-22

Click here to access the data.

1. Singh KP, Mohan D, Sinha S, et al: Impact assessment of treated/untreated wastewater toxicants discharged by sewage treatment plants on health, agricultural, and environmental quality in the wastewater disposal area. Chemosphere. 2004; 55(2): 227-255.

PubMed Abstract | Publisher Full Text

2. Kolpin DW, Furlong ET, Meyer MT, et al:: Pharmaceuticals, hormones, and other organic wastewater contaminants in U.S. streams, 1999-2000: a national reconnaissance. Environ Sci Technol. 2002; 36(6): 1202-1211. PubMed Abstract | Publisher Full Text

3. United Nations Educational, Scientific and Cultural Organization: World Water Assessment Programme, Water for People, Water for Life-the United Nations World Water Development Report. Berghahn Books: Barcelona, 2003. Reference Source

4. Todd J, Brown EJ, Wells E: Ecological design applied. Ecol Eng. 2003; 20(5): 421-440.

Publisher Full Text

5. Odum HT: Environment, power, and society for the twenty-first century: the hierarchy of energy. New York: Columbia University Press. xiv, 2007; 418. Reference Source

6. Todd J, Josephson B: The design of living technologies for waste treatment. Ecol Eng. 1996; 6(1-3): 109-136.

Publisher Full Text

7. Matamoros V, García J, Bayona JM: Organic micropollutant removal in a fullscale surface flow constructed wetland fed with secondary effluent. Water Res. 2008; 42(3): 653-660.

PubMed Abstract | Publisher Full Text

8. Vymazal J: Horizontal sub-surface flow and hybrid constructed wetlands systems for wastewater treatment. Ecol Eng. 2005; 25(5): 478-490. Publisher Full Text

9. Lee $\mathrm{CO}$, Howe $\mathrm{KJ}$, Thomson BM: Ozone and biofiltration as an alternative to reverse osmosis for removing PPCPs and micropollutants from treated wastewater. Water Res. 2012; 46(4): 1005-1014. PubMed Abstract | Publisher Full Text

10. Reungoat J, Escher $\mathrm{BI}$, Macova M, et al.: Biofiltration of wastewater treatment plant effluent: effective removal of pharmaceuticals and personal care products and reduction of toxicity. Water Res. 2011; 45(9): 2751-2762. PubMed Abstract | Publisher Full Text

11. Shrivastava P: Environmental technologies and competitive advantage. Strategic Manage J. 1995; 16(S1): 183-200.

Publisher Full Text

12. Etnier $\mathrm{C}$, Guterstam Br: Ecological engineering for wastewater treatment. 2nd ed. Boca Raton: CRC Press. 1997; 451.

Reference Source

13. Shao L, Wu Z, Zeng L, et al.: Embodied energy assessment for ecological wastewater treatment by a constructed wetland. Ecol Model. 2013; 252: 63-71. Publisher Full Text

14. Daims $\mathrm{H}$, Taylor MW, Wagner M: Wastewater treatment: a model system for microbial ecology. Trends Biotechnol. 2006; 24(11): 483-489. PubMed Abstract | Publisher Full Text

15. Truu M, Juhanson J, Truu J: Microbial biomass, activity and community composition in constructed wetlands. Sci Total Environ. 2009; 407(13): 3958-3971.

PubMed Abstract | Publisher Full Text

16. Pilon-Smits E: Phytoremediation. Annu Rev Plant Biol. 2005; 56: 15-39. PubMed Abstract | Publisher Full Text

17. Rovira AD: Plant root excretions in relation to the rhizosphere effect. Plant and Soil. 1956; 7(2): 178-194. Publisher Full Text

18. Chekol T, Vough LR, Chaney RL: Phytoremediation of polychlorinated biphenylcontaminated soils: the rhizosphere effect. Environ Int. 2004; 30(6): 799-804. PubMed Abstract | Publisher Full Text

19. Donnelly PK, Hegde RS, Fletcher JS: Growth of PCB-degrading bacteria on compounds from photosynthetic plants. Chemosphere. 1994; 28(5): 981-988. Publisher Full Text
20. Toussaint JP, Pham TT, Barriault D, et al.: Plant exudates promote PCB degradation by a rhodococcal rhizobacteria. Applied microbiology and biotechnology. 2012; 95(6): 1589-1603.

PubMed Abstract | Publisher Full Text

21. Haby PA, Crowley DE: Biodegradation of 3-chlorobenzoate as affected by rhizodeposition and selected carbon substrates. J Environ Qual. 1995; 25(2): 304-310.

Publisher Full Text

22. $\mathrm{Yi} \mathrm{H}$, Crowley DE: Biostimulation of PAH degradation with plants containing high concentrations of linoleic acid. Environ Sci Technol. 2007; 41(12): 4382-4388.

PubMed Abstract | Publisher Full Text

23. Singer AC, Crowley DE, Thompson IP: Secondary plant metabolites in phytoremediation and biotransformation. Trends Biotechnol. 2003; 21(3): $123-130$.

PubMed Abstract | Publisher Full Text

24. Singer AC, Wong CS, Crowley DE: Differential enantioselective transformation of atropisomeric polychlorinated biphenyls by multiple bacterial strains with different inducing compounds. Appl Environ Microbiol. 2002; 68(11): 5756-5759. PubMed Abstract | Publisher Full Text | Free Full Text

25. Suttinun $\mathrm{O}$, Müller R, Luepromchai E: Cometabolic degradation of trichloroethene by Rhodococcus sp. strain L4 immobilized on plant materials rich in essential oils. Appl Environ Microbiol. 2010; 76(14): 4684-4690. PubMed Abstract | Publisher Full Text | Free Full Text

26. Ferrer I, Zweigenbaum JA, Thurman EM: Analysis of 70 Environmental Protection Agency priority pharmaceuticals in water by EPA Method 1694. J Chromatogr A. 2010; 1217(36): 5674-5686.

PubMed Abstract | Publisher Full Text

27. EPA: Method 1697: Pharmaceuticals and Persona ICare Products in Water, Soil, Sediments, and Biosolids by HPLC/MS/MS. 2007; [cited 2016 6/13/2016]. Reference Source

28. Atlas RM: Handbook of microbiological media. Fourth Edition, CRC press; 2010 Reference Source

29. Bolger AM, Lohse M, Usadel B: Trimmomatic: a flexible trimmer for Illumina sequence data. Bioinformatics. 2014; 30(15): 2114-20. PubMed Abstract | Publisher Full Text | Free Full Text

30. Langmead B, Trapnell C, Pop M, et al.: Ultrafast and memory-efficient alignment of short DNA sequences to the human genome. Genome Biol. 2009; 10(3): R25. PubMed Abstract | Publisher Full Text | Free Full Text

31. Zhao $\mathrm{Y}$, Tang $\mathrm{H}, \mathrm{Ye}$ Y: RAPSearch2: a fast and memory-efficient protein similarity search tool for next-generation sequencing data. Bioinformatics. 2012; 28(1): 125-6.

PubMed Abstract | Publisher Full Text | Free Full Text

32. Buchfink $B, X i e ~ C$, Huson $D H$ : Fast and sensitive protein alignment using DIAMOND. Nat Methods. 2015; 12(1): 59-60. PubMed Abstract | Publisher Full Text

33. Huson DH, Mitra S, Ruscheweyh $\mathrm{HJ}$, et al:: Integrative analysis of environmental sequences using MEGAN4. Genome Res. 2011; 21(9): 1552-60. PubMed Abstract | Publisher Full Text | Free Full Text

34. Mitra S, Gilbert JA, Field D, et al:: Comparison of multiple metagenomes using phylogenetic networks based on ecological indices. ISME J. 2010; 4(10): 1236-42.

PubMed Abstract | Publisher Full Text

35. Overbeek R, Begley T, Butler RM, et al:: The subsystems approach to genome annotation and its use in the project to annotate 1000 genomes. Nucleic Acids Res. 2005; 33(17): 5691-702. PubMed Abstract | Publisher Full Text | Free Full Text

36. Kanehisa M, Goto S, Sato Y, et al.: KEGG for integration and interpretation of large-scale molecular data sets. Nucleic Acids Res. 2012; 40(Database issue): D109-14.

PubMed Abstract | Publisher Full Text | Free Full Text

37. Tatusov RL, Galperin MY, Natale DA, et al:: The COG database: a tool for genome-scale analysis of protein functions and evolution. Nucleic acids research. 2000; 28(1): 33-36.

PubMed Abstract | Publisher Full Text | Free Full Text 
38. Goodall DW: A probabilistic similarity index. Nature. 1964; 203: 1098. Publisher Full Text

39. Bryant D, Moulton V: Neighbor-net: an agglomerative method for the construction of phylogenetic networks. Mol Biol Evol. 2004; 21(2): 255-265. PubMed Abstract | Publisher Full Tex

40. Parks DH, Tyson GW, Hugenholtz P, et al: STAMP: statistical analysis of taxonomic and functional profiles. Bioinformatics. 2014; 30(21): 3123-3124. PubMed Abstract | Publisher Full Text | Free Full Text

41. Krzywinski M, Schein J, Birol I, et al:: Circos: an information aesthetic for comparative genomics. Genome Res. 2009; 19(9): 1639-1645. PubMed Abstract | Publisher Full Text | Free Full Text

42. Center VAoAI: Visitor Traffic Statistics. 2013; [cited 2016 6/13/2016]. Reference Source

43. Drobniewski FA: Bacillus cereus and related species. Clin Microbiol Rev. 1993 6(4): 324-338

PubMed Abstract | Publisher Full Text | Free Full Text

44. Xia K, Bhandari A, Das K, et al:: Occurrence and fate of pharmaceuticals and personal care products (PPCPs) in biosolids. J Environ Qual. 2005; 34(1): 91-104.

PubMed Abstract | Publisher Full Text

45. Suárez S, Carballa M, Omil F, et al:: How are pharmaceutical and personal care products (PPCPs) removed from urban wastewaters? Reviews in Environmental Science and Bio/Technology. 2008; 7(2): 125-138. Publisher Full Text

46. Dobbs RA, Wang L, Govind R: Sorption of toxic organic compounds on wastewater solids: correlation with fundamental properties. Environ $\mathrm{Sc}$ Technol. 1989; 23(9): 1092-1097. Publisher Full Text

47. Carballa $M$, Fink $G$, Omil $F$, et al: Determination of the solid-water distribution coefficient $\left(K_{d}\right)$ for pharmaceuticals, estrogens and musk fragrances in digested sludge. Water Res. 2008; 42(1-2): 287-295. PubMed Abstract | Publisher Full Text

48. Oulton RL, Kohn T, Cwiertny DM: Pharmaceuticals and personal care products in effluent matrices: A survey of transformation and removal during wastewater treatment and implications for wastewater management. J Environ Monit. 2010; 12(11): 1956-1978. PubMed Abstract | Publisher Full Text

49. Lishman L, Smyth SA, Sarafin K, et al: Occurrence and reductions of pharmaceuticals and personal care products and estrogens by municipal wastewater treatment plants in Ontario, Canada. Sci Total Environ. 2006: 367(2-3): 544-558

PubMed Abstract | Publisher Full Text

50. Carballa M, Omil F, Lema JM, et al:: Behavior of pharmaceuticals, cosmetics and hormones in a sewage treatment plant. Water Res. 2004; 38(12): 2918-2926.

PubMed Abstract | Publisher Full Text

51. Shon H, Vigneswaran S, Snyder S: Effluent organic matter (EfOM) in wastewater: constituents, effects, and treatment. Crit Rev Environ Sci Technol. 2006; 36(4): 327-374

Publisher Full Text

52. Boreen AL, Arnold WA, McNeill K: Photodegradation of pharmaceuticals in the aquatic environment: a review. Aquatic Sciences. 2003; 65(4): 320-341. Publisher Full Text

53. Boreen AL, Arnold WA, McNeill K: Photochemical fate of sulfa drugs in the aquatic environment: sulfa drugs containing five-membered heterocyclic groups. Environ Sci Technol. 2004; 38(14): 3933-3940. PubMed Abstract | Publisher Full Text

54. Onesios KM, Yu JT, Bouwer EJ: Biodegradation and removal of pharmaceuticals and personal care products in treatment systems: a review. Biodegradation. 2009; 20(4): 441-466. PubMed Abstract | Publisher Full Text

55. Pérez S, Eichhorn P, Aga DS: Evaluating the biodegradability of sulfamethazine, sulfamethoxazole, sulfathiazole, and trimethoprim at different stages of sewage treatment. Environ Toxicol Chem. 2005; 24(6): 1361-1367. PubMed Abstract | Publisher Full Text

56. Karnjanapiboonwong A, Morse AN, Maul JD, et al:: Sorption of estrogens, triclosan, and caffeine in a sandy loam and a silt loam soil. $J$ Soils Sediments. 2010; 10(7): 1300-1307.

Publisher Full Text

57. Batt AL, Kim S, Aga DS: Comparison of the occurrence of antibiotics in four full-scale wastewater treatment plants with varying designs and operations. Chemosphere. 2007; 68(3): 428-435. PubMed Abstract | Publisher Full Text

58. Segata N, Haake SK, Mannon P, et al.: Composition of the adult digestive tract bacterial microbiome based on seven mouth surfaces, tonsils, throat and stool samples. Genome Biol. 2012; 13(6): R42. PubMed Abstract | Publisher Full Text | Free Full Text

59. Lee S, Geller JT, Torok T, et al.: Characterization of wastewater treatment plant microbial communities and the effects of carbon sources on diversity in laboratory models. PLoS One. 2014; 9(8): e105689. PubMed Abstract | Publisher Full Text | Free Full Text
60. McLellan SL, Huse SM, Mueller-Spitz SR, et al.: Diversity and population structure of sewage derived microorganisms in wastewater treatment plant influent. Environ Microbiol. 2010; 12(2): 378-392.

PubMed Abstract | Publisher Full Text | Free Full Text

61. Shanks OC, Newton RJ, Kelty CA, et al.: Comparison of the microbial community structures of untreated wastewaters from different geographic locales. Appl Environ Microbiol. 2013; 79(9): 2906-2913. PubMed Abstract | Publisher Full Text | Free Full Text

62. Yang $\mathrm{Y}, \mathrm{Yu} \mathrm{K}, \mathrm{Xia} \mathrm{Y}$, et al:: Metagenomic analysis of sludge from full-scale anaerobic digesters operated in municipal wastewater treatment plants. App Microbiol Biotechnol. 2014; 98(12): 5709-5718. PubMed Abstract | Publisher Full Text

63. Ju F, Guo F, Ye L, et al.: Metagenomic analysis on seasonal microbial variations of activated sludge from a full scale wastewater treatment plant over 4 years. Environ Microbiol Rep. 2014; 6(1): 80-89. PubMed Abstract | Publisher Full Text

64. Fernandez-Fontaina E, Gomes IB, Aga DS, et al.: Biotransformation of pharmaceuticals under nitrification, nitratation and heterotrophic conditions. Sci Total Environ. 2016; 541: 1439-1447. PubMed Abstract | Publisher Full Text

65. Fernandez-Fontaina E, Omil F, Lema JM, et al:: Influence of nitrifying conditions on the biodegradation and sorption of emerging micropollutants. Water Res. 2012; 46(16): 5434-5444. PubMed Abstract | Publisher Full Text

66. Banerjee A, Ghoshal AK: Phenol degradation by Bacillus cereus: pathway and kinetic modeling. Bioresour Technol. 2010; 101(14): 5501-5507. PubMed Abstract | Publisher Full Tex

67. Das K, Mukherjee AK: Crude petroleum-oil biodegradation efficiency of Bacillus subtilis and $P$ seudomonas aeruginosa strains isolated from a petroleum-oil contaminated soil from North-East India. Bioresour Technol. 2007; 98(7): 1339-1345.

PubMed Abstract | Publisher Full Text

68. Ye J, Singh A, Ward OP: Biodegradation of nitroaromatics and other nitrogencontaining xenobiotics. World J Microbiol Biotechnol. 2004; 20(2): 117-135. Publisher Full Text

69. Lončar N, Božić N, Lopez-Santin J, et al.: Bacillus amyloliquefaciens laccase-from soil bacteria to recombinant enzyme for wastewater decolorization. Bioresour Technol. 2013; 147: 177-183. PubMed Abstract | Publisher Full Tex

70. Narhi LO, Fulco AJ: Identification and characterization of two functional domains in cytochrome $\mathrm{P}-450_{\mathrm{BM}-3}$, a catalytically self-sufficient monooxygenase induced by barbiturates in Bacillus megaterium. $J$ Biol Chem 1987; 262(14): 6683-6690. PubMed Abstract

71. Yoshida N, Ye L, Baba D, et al:: A novel Dehalobacter species is involved in extensive 4,5,6,7-tetrachlorophthalide dechlorination. Appl Environ Microbiol. 2009; 75(8): 2400-2405.

PubMed Abstract | Publisher Full Text | Free Full Text

72. Yoshida N, Ye L, Baba D, et al:: Reductive Dechlorination of Polychlorinated Biphenyls and Dibenzo-p-Dioxins in an Enrichment Culture Containing Dehalobacter Species . Microbes Environ. 2009; 24(4): 343-346. PubMed Abstract | Publisher Full Text

73. Li Z, Yoshida N, Wang A et al: Anaerobic mineralization of 2,4,6-tribromopheno to $\mathrm{CO}_{2}$ by a synthetic microbial community comprising Clostridium, Dehalobacter, and Desulfatiglans. Bioresour Technol. 2015.176: 225-232. PubMed Abstract | Publisher Full Text

74. Punj S, John GH: Purification and identification of an FMN-dependent NAD(P)H azoreductase from Enterococcus faecalis. Curr Issues Mol Biol. 2009; 11(2): $59-65$.

PubMed Abstract

75. Cerniglia CE: Biodegradation of polycyclic aromatic hydrocarbons Biodegradation. 1992; 3(2-3): 351-368. Publisher Full Text

76. Moody J, Doerge DR, Freeman JP, et al:: Degradation of biphenyl by Mycobacterium sp. strain PYR-1. Appl Microbiol Biotechnol. 2002; 58(3): 364-369.

PubMed Abstract | Publisher Full Text

77. Besse $\mathrm{P}$, Combourieua $\mathrm{B}$, Poupin $\mathrm{P}$, et al.: Degradation of morpholine and thiomorpholine by an environmental Mycobacterium involves a cytochrome P450. Direct evidence of intermediates by in situ ${ }^{1} \mathrm{H}$ NMR. $J$ Mol Catal B Enzym. 1998; 5(1-4): 403-409. Publisher Full Text

78. Esplugas M, González O, Sans C: Bacterial community characterization of a sequencing batch reactor treating pre-ozonized sulfamethoxazole in water. Environ Technol. 2013; 34(9-12): 1583-1591.

PubMed Abstract | Publisher Full Text

79. Herbst FA, et al:: Elucidation of in situ polycyclic aromatic hydrocarbon degradation by functional metaproteomics (protein-SIP). Proteomics. 2013; 13(18-19): 2910-2920. PubMed Abstract | Publisher Full Text

80. Jeon CO, Madsen EL: In situ microbial metabolism of aromatic-hydrocarbon 
environmental pollutants. Curr Opin Biotechnol. 2013; 24(3): 474-481. PubMed Abstract | Publisher Full Text

81. De Gusseme B, Vanhaecke L, Verstraete W, et al.: Degradation of acetaminophen by Delftia tsuruhatensis and Pseudomonas aeruginosa in a membrane bioreactor. Water Res. 2011; 45(4): 1829-1837.

PubMed Abstract | Publisher Full Text

82. Shourian M, Noghabi KA, Zahiri HS, et al: Efficient phenol degradation by a newly characterized Pseudomonas sp. SA01 isolated from pharmaceutical wastewaters. Desalination. 2009; 246(1-3): 577-594.

Publisher Full Text

83. Benotti MJ, Brownawell BJ: Microbial degradation of pharmaceuticals in estuarine and coastal seawater. Environ Pollut. 2009; 157(3): 994-1002.

PubMed Abstract | Publisher Full Text
84. Top EM, Springael D: The role of mobile genetic elements in bacterial adaptation to xenobiotic organic compounds. Curr Opin Biotechnol. 2003; 14(3): 262-269. PubMed Abstract | Publisher Full Text

85. Staley JT, Konopka A: Measurement of in situ activities of nonphotosynthetic microorganisms in aquatic and terrestrial habitats. Annu Rev Microbiol. 1985; 39(1): 321-346.

PubMed Abstract | Publisher Full Text

86. van der Meer JR, de Vos WM, Harayama S, et al:: Molecular mechanisms of genetic adaptation to xenobiotic compounds. Microbiol Rev. 1992; 56(4): 677-694. PubMed Abstract | Free Full Text

87. Díaz E: Bacterial degradation of aromatic pollutants: a paradigm of metabolic versatility. Int Microbiol. 2004; 7(3): 173-180.

PubMed Abstract 


\section{Open Peer Review}

\section{Current Peer Review Status:}

\section{Version 1}

Reviewer Report 14 November 2016

https://doi.org/10.5256/f1000research.9854.r17273

(C) 2016 Singer A. This is an open access peer review report distributed under the terms of the Creative Commons Attribution License, which permits unrestricted use, distribution, and reproduction in any medium, provided the original work is properly cited.

\section{Andrew C. Singer}

NERC (Natural Environment Research Council) Centre for Ecology \& Hydrology (CEH) , Wallingford, UK

I found this to be an interesting field-based study. It is limited by all the typical factors that one finds in a field-based study (i.e., replication, no controls, etc), but that is to be expected and okay so long as the analysis and interpretation are consistent with theses limitations. I feel the authors largely stayed true to their experimental design and offered some useful insights into the processes of an ecological WWTP. I only have a few trivial suggestions to for (potentially) improving some elements of the paper, although it reads well and could largely remain as it stands.

Specific suggestions:

Would it be appropriate to denote "ecological wastewater treatment plants" as eWWTP, as they are clearly different from WWTPs in this context.

The aim of the study does not immediately follow from the sentence in the abstract: "To determine whether the removal of micropollutants in ecological wastewater treatment plants (WWTPs) is promoted by the plant-microbe interactions..."

You are assessing the correlation between wastewater input, treatment stage, PPCP removal, bacterial family and gene prevalence in plant and sand biofilms, planktonic cells and enrichment cultures.

Granted there's no easy way to summarize this, but it is a more accurate description of the paper. You may wish to adjust the abstract to better reflect what was done.

Sampling: It's not clear how samples were collected from the eWWTP, the replication or pooling that was done, the transportation conditions and storage. Clarify when sampling was of water and/or biofilm and depth of sample acquisition and whether roots were removed or scraped for the biofilm (and the sand filter?). The environmental conditions in the eWWTP need to be provided 
(temp, $\mathrm{pH}$, atmosphere, etc).

The observation that biodegradation/metabolism is dominated by benzoate degradation is quite interesting and leads to some useful insight into what might be going on in the eWWTP. It might be an option to make this a focus of the paper, i.e., in the title. If you choose to do this you might then rearrange the results to put this first as the sequence information really just supports this one result.

Competing Interests: No competing interests were disclosed.

\section{I confirm that I have read this submission and believe that I have an appropriate level of expertise to confirm that it is of an acceptable scientific standard.}

Reviewer Report 27 September 2016

https://doi.org/10.5256/f1000research.9854.r16355

(c) 2016 Kirkup B. This is an open access peer review report distributed under the terms of the Creative Commons Attribution License, which permits unrestricted use, distribution, and reproduction in any medium, provided the original work is properly cited.

\section{Benjamin C. Kirkup}

US Naval Research Laboratory, Washington, DC, USA

In reviewing "Metagenomic analysis of an ecological wastewater treatment plant's microbial communities and their potential to metabolize pharmaceuticals," I consider the intended breadth of the paper. The paper would accurately be described as a first look at a single 'ecological wastewater treatment plant' through the somewhat particular lenses of metagenomics and micropollutants.

Micropollutants are not the primary target of wastewater treatment; prevention of infectious disease motivated the first sand filters and avoiding eutrophication or other bulk pollution is a common goal, which explains the focus on nitrogen, dissolved organic carbon, phosphorus, etc. Micropollutants are not successfully managed by most wastewater treatment paradigms, as the authors discuss. The authors integrated a number of methods to characterize micropollutants and communities in small-scale wastewater treatment facility that integrates plants and microbes into the treatment process. In general, the authors seem to be advocates for the special treatment process; the intention is to evaluate the processing of these recalcitrant pollutants; but no direct comparison is made to other processes.

A single facility was sampled across the process at a single time. Input wastewater and waste in process was sampled and the influent and resident micropollutants were quantified.

The enrichment cultures were performed with each of three pharmaceuticals as the sole carbon source, in replicate. Of 15 replicates, eight were selected based on visual inspection for microbial growth. 


\section{Methods and Results:}

I do not have the background to critique the micropollutant quantification, which was done at a commercial lab using standard EPA methods.

There are substantial problems with the sequencing methods. The shotgun metagenomics was done without a kit (true negative) control or a positive (synthetic) community standard. In addition, no standards were used to assess DNA extraction biases (such as reported by ${ }^{13}$. The EZNA Mollusc DNA kit was used; I am not sufficiently familiar with this specific kit, compared to the bacterial kits, for example. This is the only case in which that kit is used in bacterial shotgun metagenomics, to my knowledge. I do not know what kinds of bias this introduces to the analysis. Overall, the use of non-standard methods requires new controls; some of which should be performed even when standard methods are employed. Comparisons to non-sequencing methods (ie. microscopy, flow cytometry, qPCR from several DNA extractions) would also inform evaluation of bias and uncertainty.

The bioinformatic methods reveal problems interpreting the data. MEGAN is the core of the bioinformatics pipeline, which was tested on two existing synthetic datasets. $\sim 11-12 \%$ of the reads were excluded for quality. 50-60\% of the remaining reads were protein reads from NCBI. However, environmental and enrichment culture reads differed greatly in their assignment to known taxonomy. Almost all enrichment culture reads were assigned; only $80 \%$ of the quality and protein reads from the environment could be assigned.

Eukaryotes account for a substantial fraction of the reads in HR2_B, but not in the others samples. Fungi are specifically reported in the enrichment cultures, suggesting that eukaryotes are indeed sequenced and analyzed. Given all this information, the lack of plant DNA in the other HR samples is counter-intuitive. Typically, host-associated shotgun metagenomic sequencing effort would benefit from draft host genome sequencing, to allow the host DNA to be removed bioinformatically (the way it was with the PhiX spike-in). Alternative (wet) methods to remove host DNA are also not evident.

The reported microbial community compositions are unexpectedly simple. Perhaps the depth of sampling was inadequate; this could be assessed with a method such as $16 \mathrm{~S}$ rRNA sequencing at a greater depth. The comparison of 'taxonomic,' 'community,' or 'metabolic' structures is undermined by the need to map reads to the KEGG database without assembly and with a very low rate of read mapping to NCBI proteins. Further, rarefaction (normalizing the total number of reads) is problematic ${ }^{2}$. Given the difficulties with data analysis, however, it seems unnecessary to give a detailed critique of the downstream analyses.

Some organisms were present in the original samples which apparently survived in the enrichment culture. Some of these have been identified by sequencing, but it is unclear how many more may be present. No attempt was made to return to the original samples with probes for the organisms found during enrichment, nor were genomes assembled. With a significantly greater number of enrichments, multi-sample strategies might have been used to assemble genomes from distinct organisms ${ }^{4}$. These could be used to map reads from the original samples.

\section{Conclusions:}


Given that so few samples were examined, the study is best scaled to pilot a larger examination of similar treatment facilities. Samples were not studied in technical replicate, nor repeated in space across the tanks, nor across time at short and long time scales, or across related facilities, or facilities with other processing strategies. No experiments were performed which perturbed or altered the plant or microbial processes in the facility.

As a result, most of the conclusions must be drawn with very limited statistical evaluation. Most of the conclusions are not effectively supported because the sample variance could not be estimated. Conclusions like "The aqueous microbial metagenome, collectively, contained a greater total for xenobiotic metabolism gene copies..." are unsupported.

A starting hypothesis is that the fraction of reads from a sample assigned to xenobiotic degradation is indistinguishable from sample to sample, rather than being ordered ("produced the greatest number of sequences..."). Similarly, statements about the taxonomy ("relative abundance of Bacilli in the immersed biofilm communities was highly variable") are unsupported by the data.

The "role of plants" ("The role plants have on influencing the structure of the root-colonizing microbial communities appeared to increase after the first three treatment tanks") could not be examined by single observations of the root and water within individual tanks. Nor could conclusions be reached about microbial community variation over time (see: "are likely to change with time, fluctuating..."), given that only a single time point was sampled. The results do not indicate that "the ecological WWTP is performing well with regard to attenuating fecal coliforms" given that infection can be caused by a low number of cells and the sensitivity of the sequencing to minor populations was uncharacterized.

The discussion of phase partitioning of micropollutants ("PPCPs in the wastewater" and "Removal of PPCPs by the ecological WWTP") is outside my area of expertise.

Generalization of microbial behavior at the level of species is problematic, particularly when inferring activity on complex organic substrates. Generalizing to families and phyla (Rhizobiales, Firmicutes, Mycobacteria... ) is inappropriate. Experiments with specific strains are required for effective experimental annotation of novel degradation pathways.

\section{Overall Review:}

This is an interesting pilot experiment for studies which collectively may result in conclusions of the sort reported in the paper. Method development and the sequencing of specific microbial and plant reference genomes will prepare a team for the extensive sampling and experimentation needed to assess the effectiveness and impact of this wastewater treatment strategy. The concentrations of micropollutants observed in these few samples suggest that they can be altered by such treatment, but that they also may circulate at increased concentrations as water is reused.

\section{References}

1. Albertsen M, Hansen LB, Saunders AM, Nielsen PH, et al.: A metagenome of a full-scale microbial community carrying out enhanced biological phosphorus removal.ISME J. 2012; 6 (6): 1094-106 PubMed Abstract | Publisher Full Text

2. McMurdie PJ, Holmes S: Waste not, want not: why rarefying microbiome data is inadmissible. 
PLoS Comput Biol. 2014; 10 (4): e1003531 PubMed Abstract | Publisher Full Text

3. Guo $\mathrm{F}$, Zhang T: Biases during DNA extraction of activated sludge samples revealed by high throughput sequencing.Appl Microbiol Biotechnol. 2013; 97 (10): 4607-16 PubMed Abstract | Publisher Full Text

4. Sangwan N, Xia F, Gilbert JA: Recovering complete and draft population genomes from metagenome datasets.Microbiome. 2016; 4: 8 PubMed Abstract | Publisher Full Text

Competing Interests: No competing interests were disclosed.

I confirm that I have read this submission and believe that I have an appropriate level of expertise to confirm that it is of an acceptable scientific standard, however I have significant reservations, as outlined above.

Author Response 28 Sep 2016

Ian Balcom, Lyndon State College, Lyndonville, USA

Thank you for the thoughtful review of our work and helpful feedback. We will be incorporating many of your suggestions into future studies, which will be focusing on increasing replication.

Here are responses to some of your comments on the extraction methods used here:

1. The Modified Omega Mollusc Kit protocol used in this study was modified to act as a pre -packaged CTAB kit described J Zhou and Ed Moore;

DNA recovery from soils of diverse composition. Appl Environ Microbiol. 1996 Feb;62(2):316-22. Zhou J, Bruns MA, Tiedje JM.

Simplified protocols for the preparation of genomic DNA from bacterial cultures. Molecular Microbial Ecology Manual, 2nd Edition 1.01: 3-18, 2004. E. Moore, A Arnscheidt, A. Kruger, C. Strompl, M. Mau

2. This CTAB protocol has also been described in the following manuscript with the following modifications: A pre-extraction metagenomics bacterial cell wall digestion was performed using a multi-component enzyme mix described below in the MetaSub paper. This enzyme is manufactured by Sigma and will be commercially available in Q1 2017.

The Metagenomics and Metadesign of the Subways and Urban Biomes (MetaSUB) International Consortium inaugural meeting report. The MetaSUB International Consortium. Microbiome. 2016 4:24

3. This Reference data and method is also available on the following websites:

https://abrf.org/sites/default/files/temp/RGs/MGRG/narg-meta-

2013_final_poster_forprinter.pptx

http://extrememicrobiome.org/links/ 
Comments on DNA kit Negative and Library Negatives: Our core facility runs DNA extraction kit negatives on the lot of reagents from both Sigma and Omega BioTek as a "process control" and quantifies the negative using the Qubit High Sensitivity kit. We do not sequence negative controls that have values that are below detection limit [BDL]. A Negative control is processed for each group of DNA library samples.

Comments on DNA extraction bias and microbial standards: Currently there is no approved microbial whole cell reference standards. However, the ABRF Metagenomics research group is currently in the process of distributing 6 through a collaboration with ATCC. The ABRF is the first group to make a whole cell microbial standard. Further the ABRF has assembled the Class 1 and Class1+ genomic microbial standard that will also be distributed through the ATCC.

This topic was discussed at great length at the NIST Microbiome standards meeting in Gaitherburg MD on Aug 8th as communicated by Scott Tighe. Scott Tighe is the current lab manager that performed this work, is one of four co-leaders of the NIST International Microbiome Metagenomics Standards Alliance [IMMSA] and presented these bottle necks on day 2 session 3 . It is well recognized that whole cell quantitative standards do not exist; therefore, the reviewer must understand that doing DNA extraction bias studies are a large undertaking. The ABRF-ATCC whole cell microbial Class 1 reference standard will help us understand the DNA biases in the the entire field of microbiome and not just rely on a simple MoBio protocol. It should be pointed out to the reviewer that Zymo's Zymobiotics bacterial standard is not whole cell, but rather suspended in SDS as a preservative and can not be used for DNA extraction bias studies.

https://www.nist.gov/news-events/events/2016/08/standards-microbiome-measurementsworkshop

Competing Interests: No competing interests to declare. 
The benefits of publishing with F1000Research:

- Your article is published within days, with no editorial bias

- You can publish traditional articles, null/negative results, case reports, data notes and more

- The peer review process is transparent and collaborative

- Your article is indexed in PubMed after passing peer review

- Dedicated customer support at every stage

For pre-submission enquiries, contact research@f1000.com 